\title{
Chemical shrinkage characterization techniques for thermoset resins and associated composites
}

\author{
Yasir Nawab · Salma Shahid • Nicolas Boyard • \\ Frédéric Jacquemin
}

\begin{abstract}
Control and optimization of curing process is very important for the production of high quality composite parts. Crosslinking of molecules of thermoset resin occurs in this phase, which involves exothermy of reaction, chemical shrinkage (Sh) and development of thermophysical and thermo-mechanical properties. Exact knowledge of the evolution of all these parameters is required for the better understanding and improvement of the fabrication process. Sh is one such property of thermoset matrix, which is difficult to characterize due to its coupling with thermal expansion/contraction. A number of techniques have been used to determine volume Sh of thermoset matrix, which later on has been used to find tensor of Sh for the simulation of residual stresses and shape distortion of composite part, etc. Direct characterization of volume Sh of composites has also been made by some authors. Though not much, but some work has also been reported to determine the Sh of composite part in a specific direction.
\end{abstract}

Y. Nawab ( $₫)$

Laboratoire d'Ondes et Milieux Complexes, UMR6294 CNRS,

Université du Havre, 53 rue de Prony, BP 540,

76058 Le Havre, France

e-mail: yasir.nawab@yahoo.com

S. Shahid

Normandy University, UCBN, UR ABTE EA4651, 14032 Caen, France

N. Boyard

Université de Nantes, CNRS, Laboratoire de Thermocinétique de Nantes, UMR 6607, La Chantrerie, rue Christian Pauc, BP 50609, 44306 Nantes, France

F. Jacquemin

Institut de Recherche en Génie Civil et Mécanique, UMR CNRS

6183, Université de Nantes, 37 Bd. de l'université,

BP 406, 44600 Saint-Nazaire, France
In this article, all the techniques used in the literature for the characterization of $\mathrm{Sh}$ of resin and composite are reported briefly with their respective advantages, disadvantage and important results.

\section{Introduction}

A better understanding of curing process and related phenomena such as chemical shrinkage (Sh), thermal expansion (T.E), heat transfer, reaction kinetics and properties development is required for the production of high quality thermoset composite parts. Matrix shrinkage/expansion is an important parameter to define the residual stress in a composite part [1-11] and for its shape distortion during curing [12-14]. Many defects $[15,16]$ in a composite part are produced as a result of these stresses. The matrix shrinkage can be of two origins: thermal and/or chemical but in both cases it is associated to heat transfer. During the curing, dimension variation of a part is the result of coupled thermal and chemical contributions. Certain problems such as sticking of resin or composite with the container, exothermy of reaction etc. are faced during the testing. Moreover, the strong coupling with T.E makes the calculation of Sh difficult.

ASTM standard D2566 provided [17] a simple method to measure the linear component of the apparent shrinkage of a thermoset resin casting system during cure. A half round cavity mould is filled with liquid resin. Difference between length of cured resin and the mould corresponds to the apparent shrinkage.

The true Sh is much higher than this apparent shrinkage. In fact, for a hot curing system, the T.E coefficient of resin in the liquid state is much higher than in the cured state, either above or below $\mathrm{Tg}$; this can lead to a very low apparent shrinkage masking a much higher real shrinkage. 
A capillary-type dilatometer also presents a simple method to determine the Sh of resin. Change in volume of resin in capillary tube while curing the resin at isothermal temperature corresponds to Sh. This change is recorded by visual readings or using a digital method. Sticking of resin with capillary walls was a significant problem faced in this method.

Several other methods were then developed for the determination of Sh to overcome the problems faced during measurement, improve the accuracy of measurements, and to do measurement in different conditions of temperature and pressure.

In most of the studies conducted for Sh determination, volume variation of matrix was recorded. Then volume Sh was decoupled from T.E/contraction. Characterization of volume $\mathrm{Sh}$ of composites has also been made by some authors. Though not much, but some work has also been reported to determine the linear Sh of a composite part.

In most of the studies, determination of Sh of thermosetting resins and composites was done by assuming negligible temperature gradients. For such studies, size of the resin sample is a very important factor. Larger resin sample used for shrinkage measurement releases a significant amount of heat creating local temperature gradients. Since, kinetics of reaction depends largely on temperature, it is very difficult to couple this with the kinetics determined from DSC (using a very small sample). On the other hand, small sized sample used for measurement has negligible exothermy, but there are always questions on the accuracy of shrinkage measurement.

In this review, techniques that have been used for Sh determination are discussed briefly with their respective advantages, limitations and important results.

\section{Sh determination techniques for thermoset resins}

Dilatometric techniques for the reactive polymers can be found in the literature in the beginning of 20th century [18] but the dilatometers specialized for thermoset resins were mostly developed in the second half of 20th century. Dilatometry of thermoset resins is difficult for several reasons such as early beginning of chemical reaction, rapid chemical reaction in heating ramp conditions, exothermy during the reaction, which affects the temperature hence the reaction rate control, sticking of resin with the container and deconvolution of thermal contribution when reaction occurs during heating.

When the thermoset resin is cured, it undergoes volume changes. They are due to its T.E or thermal contraction (T.C), and Sh induced by crosslinking of molecules.

Figure 1 shows the curing cycle of a typical thermoset resin (epoxy). The degree of cure is also plotted on the same graph. Possible dimensional changes because of T.E, T.C and $\mathrm{Sh}$ are also indicated. In the heating (from reference temperature $T_{0}$ to $T_{\text {cure }}$ ) step A-B, resin undergoes T.E and Sh.

Chemical shrinkage is not much significant in this step as value of degree of cure is not very high. In the constant temperature portion $\mathrm{B}-\mathrm{C}$, there will be no T.E, but resin will shrink due to Sh. In the cooling step C-D, the resin will shrink thermally. The total change in volume will be the difference of volume at point ' $A$ ' and ' $D$ ' and it depends on the temperature at which this change is measured [19].

Many techniques have been developed to measure shrinkage of resin. These techniques can be categorized in two groups (Fig. 2):

- Volume dilatometric methods

- Non-volume dilatometric methods
Fig. 1 Curing cycle of an epoxy resin
B C

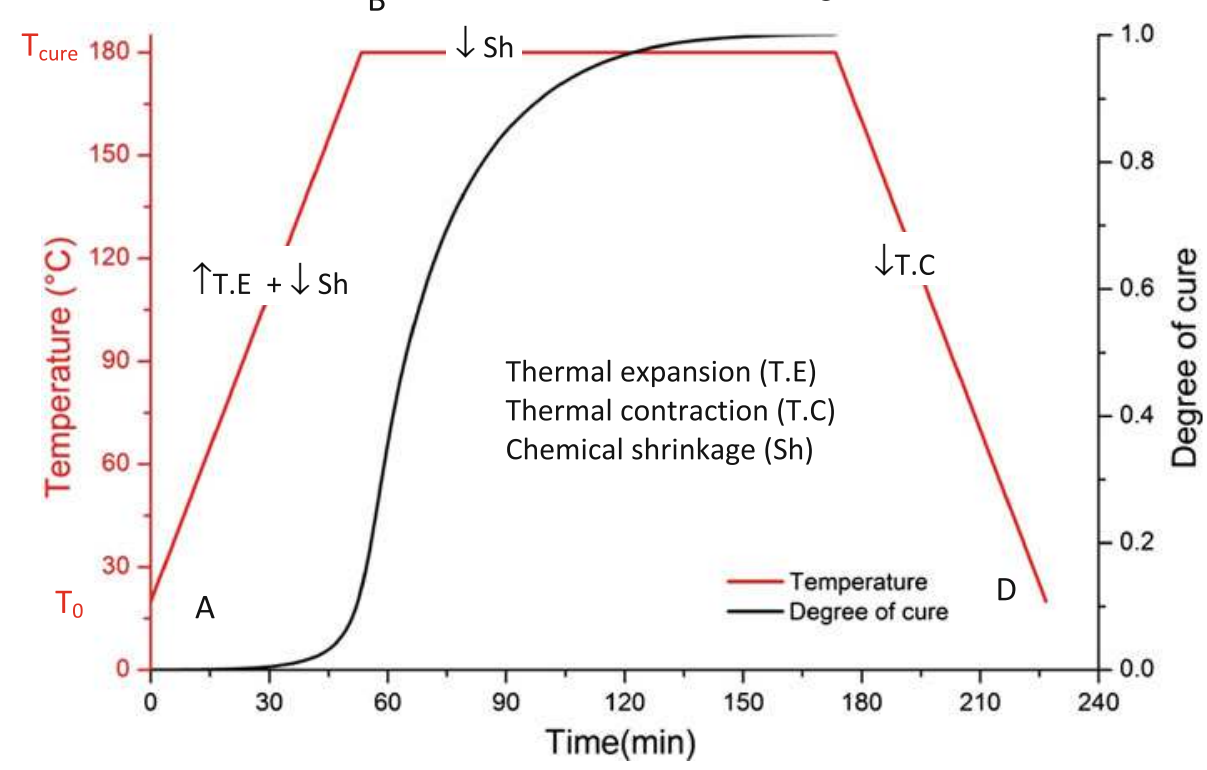




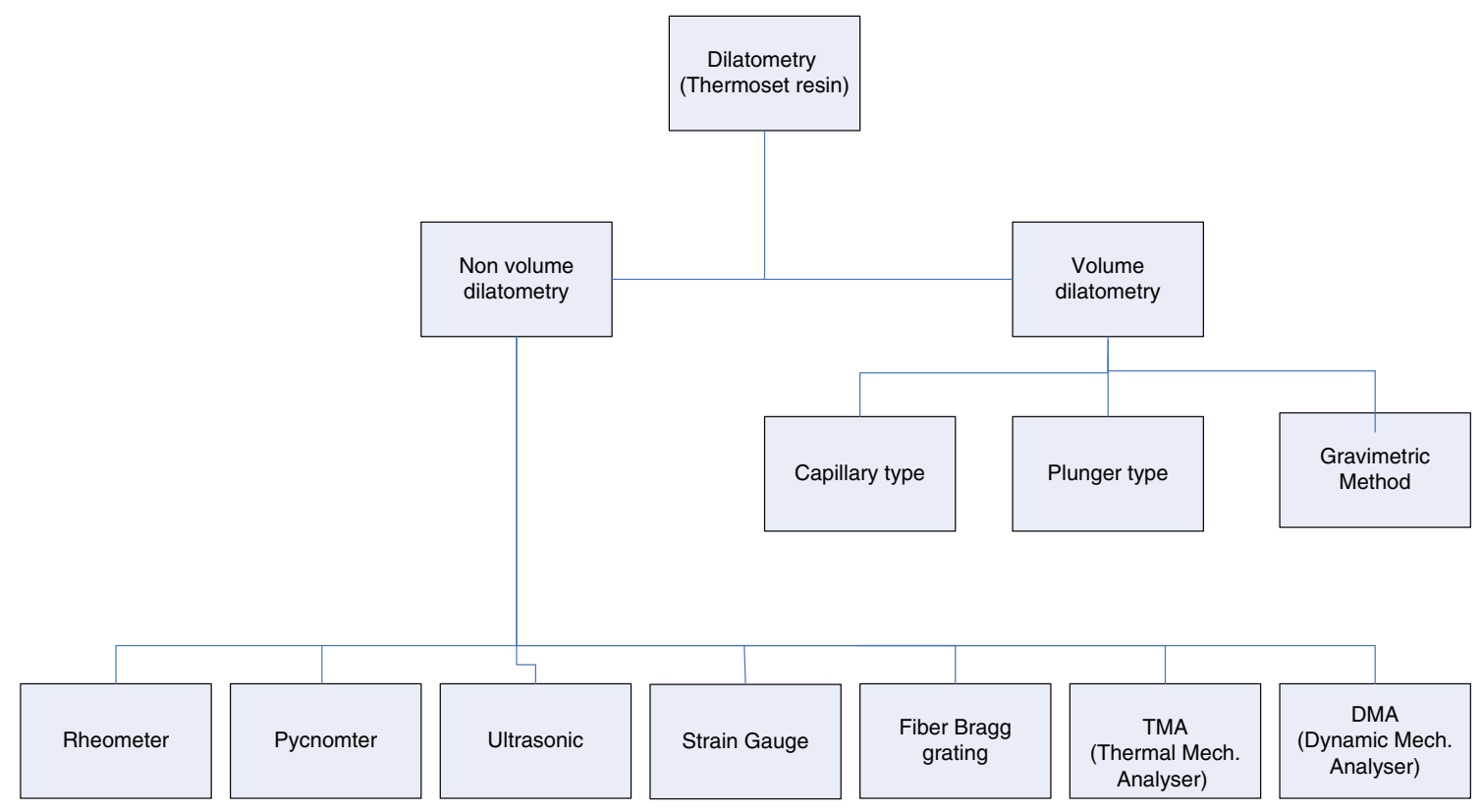

Fig. 2 An overview of matrix shrinkage measurement techniques for resin
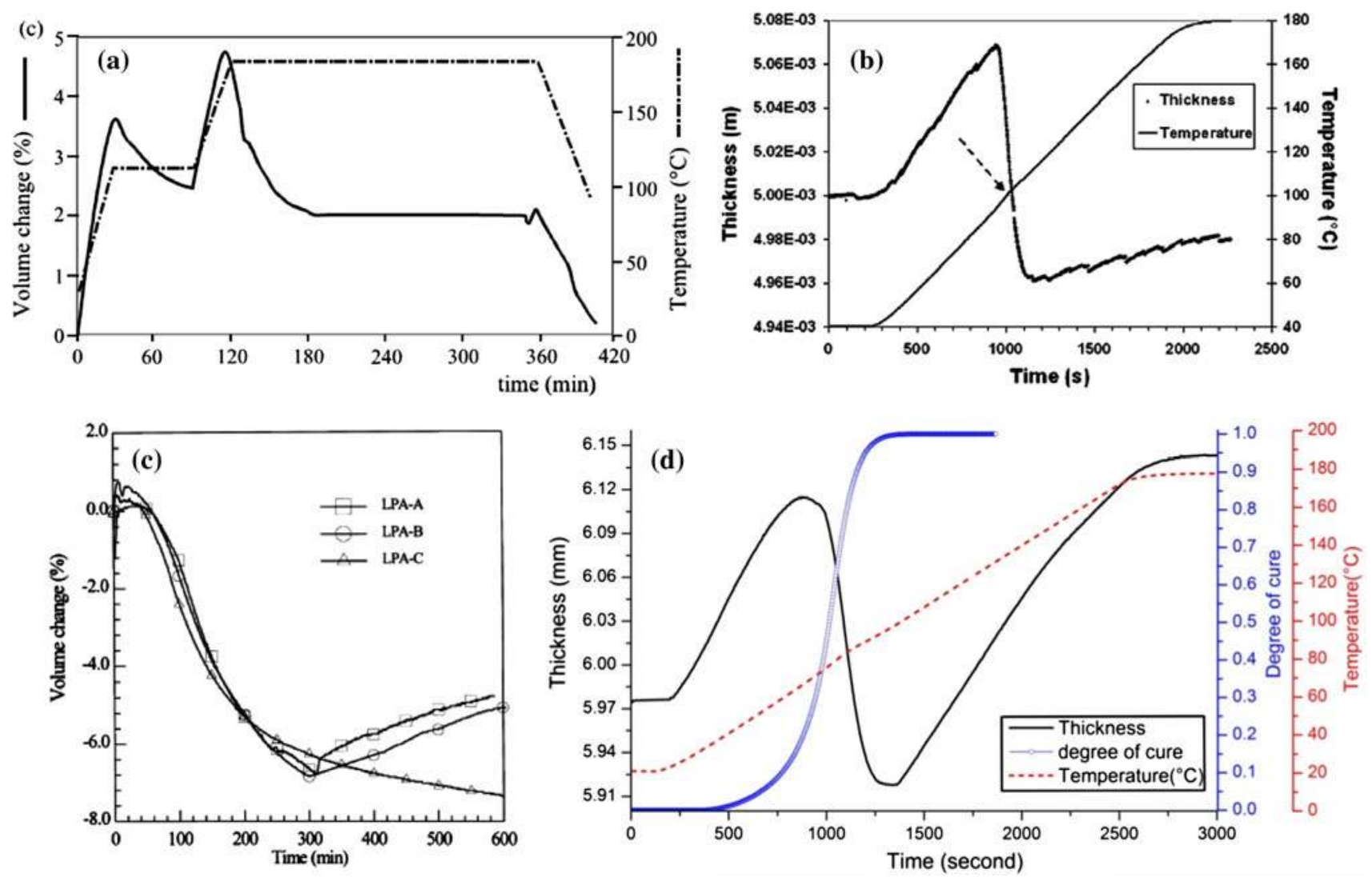

Fig. 3 Volume variation curves of different resins from literature and present study 
Both groups can be subdivided as shown in Fig. 2 to provide an overview of the mainly developed techniques for shrinkage determination.

Volume dilatometric methods

In this type of approach the change in volume is measured directly. In all these methods, Sh is derived from volume variation (dilatometric) curve. Variation of volume of resin during curing depends on its chemical formulation, curing cycle [20] and pressure applied. To give a broader view, volume variation of epoxy resin 3501-6 [21] (Fig. 3a), unsaturated polyester containing LPA [22] submitted to a heating ramp curing cycle (Fig. 3b), unsaturated polyester containing LPA cured at $35{ }^{\circ} \mathrm{C}$ [23] (Fig. 3c) are presented along with volume variation of vinylester resin (Fig. 3d) cured in heating ramp of $4{ }^{\circ} \mathrm{C} / \mathrm{min}$ [24]. A significant difference can be observed among the volume curves of the four presented (Fig. 3a-d).

The commonly known volume dilatometric methods of measurement of shrinkage can be categorized as:

- Capillary type

- Gravimetric method

- Plunger type

\section{Capillary-type dilatometer}

These dilatometers [25-27] are the simplest ones, and measure the cure shrinkage by determining the linear height change of a column of liquid such as mercury or water, which is connected to a reservoir of the liquid surrounding the test substance. They generally lack digital output of the volume change, so the precision of the measurement is largely limited by the accuracy of visual observation.

Moreover, such instruments do measurements under low pressure, which do not correspond to fabrication conditions. In addition, the sticking of resin with the walls of capillary tube results in additional errors. Therefore, this method is restricted to slow reactions, low conversions and low viscosity systems. Excellent control of temperature is required to avoid the thermal effects.

Yates and McCalla [26] developed a capillary-type dilatometer (Fig. 4a) and used it for vinylester resin and three epoxy resins. It consisted of a bulb $\mathrm{E}$ having volume of $15 \mathrm{~cm}^{3}$ for resin placement, which was connected to three limbs A, B and C. The limb ' $\mathrm{C}$ ' carrying thermocouple was extended in bulb E such that its tip was in the resin. The lower end of limb had silicon fluid which facilitated the thermal communication between resin and thermocouple. A stopper D connected to E facilitated the removal of dissolved gas.

The pre-weighted resin poured in bulb E by limb 'B' and dissolved gas were removed by vacuum through stopper $\mathrm{D}$. The meniscus level of mercury in the limb ' $\mathrm{A}$ ' gave the information about resin volume. For heating, the dilatometer was placed in a viscometer bath containing silicone fluid and controllable temperature within $T \pm 0.01{ }^{\circ} \mathrm{C}$. The movement of the meniscus in limb 'A' was monitored with the aid of a cathetometer sighted through a window in the wall of the bath.

Figure $4 \mathrm{~b}$ shows the variation of volume of vinylester resin. Thermal cycle was composed of following steps:

- Curing at $20^{\circ} \mathrm{C}$ for $24 \mathrm{~h}$,

- Heating to $100{ }^{\circ} \mathrm{C}$ and then maintained at this temperature for $3 \mathrm{~h}$ for post-curing

- Cooling to room temperature
Fig. 4 a Capillary-type dilatometer $\mathbf{b}$ volume variation of vinylester during curing [26]

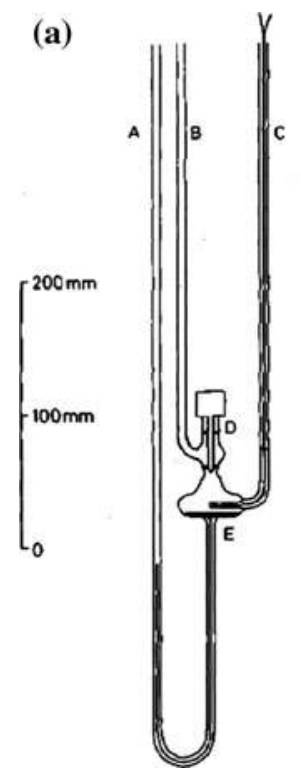

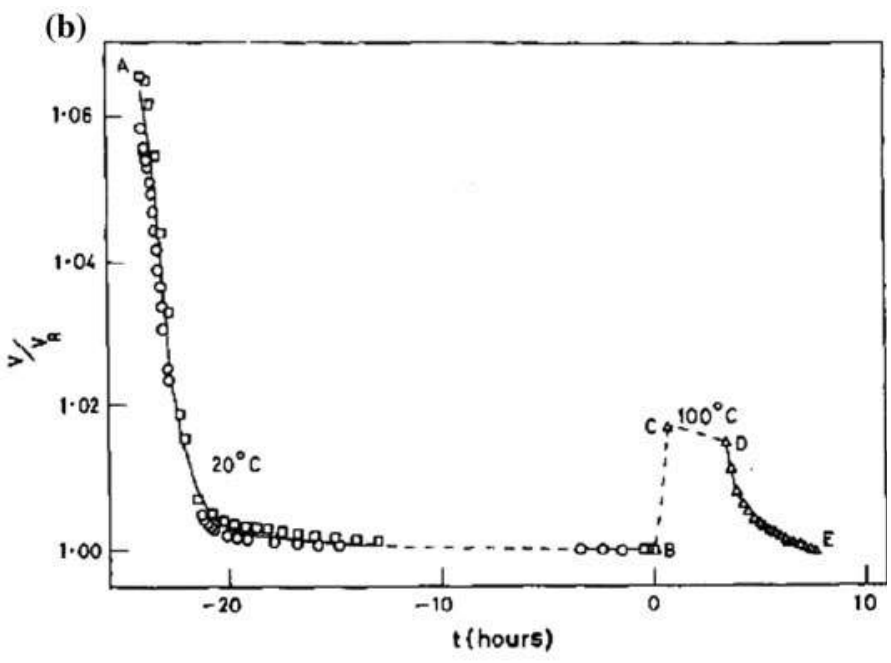


If ' $V_{\mathrm{R}}$ ' represents the volume at point $\mathrm{B}$ at the end of first isotherm, the ratio $V / V_{\mathrm{R}}$ denotes the reduced volume. Sh was represented versus time and global shrinkage was found about $6 \%$. The volume shrinkage in region CD was due to the fact that resin had not cure completely during isotherm at $20^{\circ} \mathrm{C}$ for $24 \mathrm{~h}$.

Epoxy resins were also cured in the similar way, following the manufacturer recommended thermal cycle. The overall Sh of three types of epoxy resins were found equal to 2,6 and $4 \%$, respectively. Lack of re-use of instrument was the biggest drawback of this technique.

Snow and Armistead [27] improved the instrument of Yates et al. [26] by introducing a detachable bulb, a graduated capillary and PYREX-treated glass (to overcome problem of sticking of resin with walls). Specific volume measurement as function of curing time, and T.E measurement of monomer and cured thermoset were carried out on bisphenol A dicyanate. The maximum value of cure shrinkage was found to be $19 \%$.

Huang and Liang [28] proposed a capillary-type dilatometer in which sample was contained in a bag made of high density polyethylene to avoid problem of sticking of resin with walls of instrument. This device was used to measure Sh of unsaturated polyester with four different low profile additives (for shrinkage compensation).

The system consists of a sample cell of stainless steel placed in a pressure cell (screwed at its bottom). The sample (6-10 mg) was immersed in confining fluid, i.e. mercury, whose level (on a graphite rod) indicated the variations of volume. A thermocouple inserted into the sample bag recorded the temperature variations during curing. The pressure cell partially filled with silicon oil and equipped with heating and cooling coils maintain the desired temperature and pressure. The study was carried out under $0.1 \mathrm{MPa}$ pressure. Figure 5 shows the relative polymerization shrinkage $\%$ of unsaturated polyester containing $10 \%$ PVAc additive as

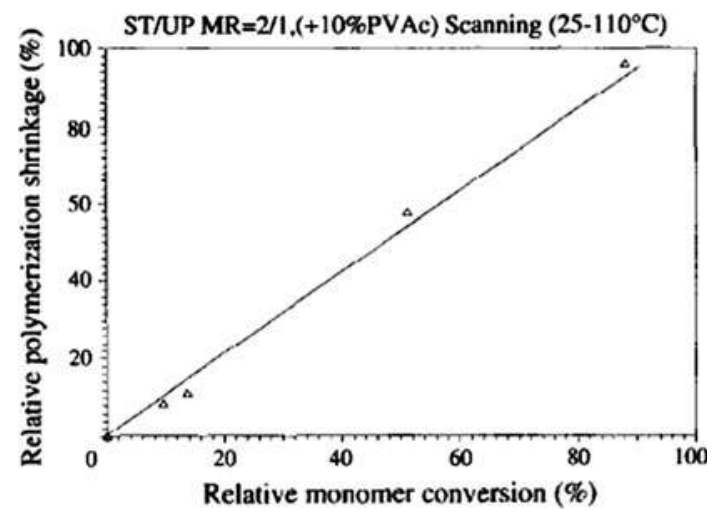

Fig. 5 Relationship between the relative polymerization shrinkage measured at $110{ }^{\circ} \mathrm{C}$ and the relative monomer conversion progresses for UP resins [28] function of relative monomer conversion $\%$ (measured by DSC), when final curing was done at $110{ }^{\circ} \mathrm{C}$. One can observe a linear relationship between resin shrinkage and conversion degree. Visual measurement remains the limitation of the device.

\section{Gravimetric method}

Gravimetric method is based on the monitoring the change in buoyancy of the resin [19]. This method was used to measure Sh of the epoxy resin system during an isothermal cure [19, 29, 30]. Resin was weighed independently of the bath and was suspended in a pot of fluid, regulated to the curing temperature (Fig. 6).

Provided the density of the fluid is known, the Sh of the resin can be monitored during an isothermal cure. The resin system was sealed in a silicone rubber bag to avoid the disturbance of chemical reactions of the resin by any other medium such as air or moisture.

Furthermore, the soft and flexible silicone bags kept the resin stress-free during the measurement regardless of the state of the resin; therefore, the precise cure shrinkage of the resin as a function of time at the curing temperature was measured.

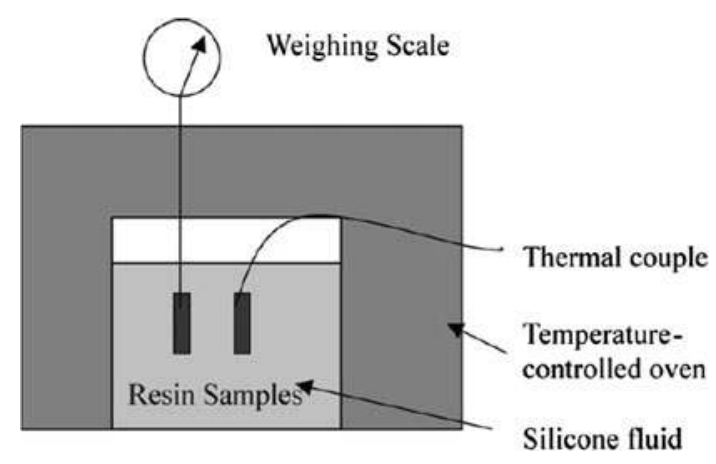

Fig. 6 Test setup of Gravimetric method [19]

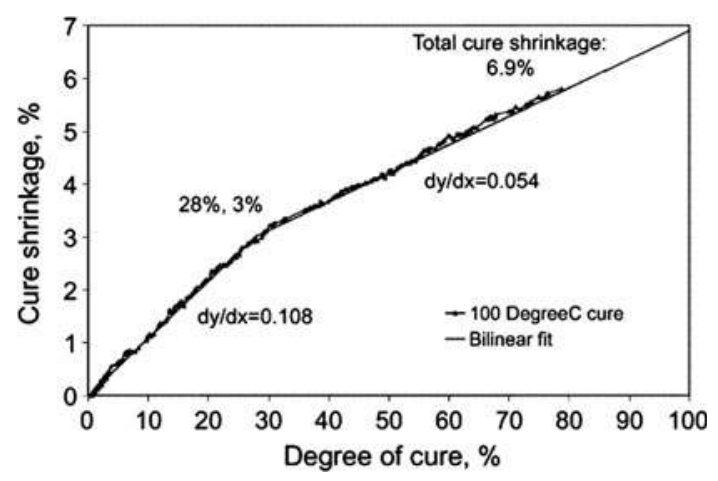

Fig. 7 Chemical shrinkage of epoxy resin versus degree of cure for $100{ }^{\circ} \mathrm{C}$ isothermal cure based on FTIR cure kinetics [19] 
The relationship between the cure shrinkage and degree of cure was deduced from the knowledge of the cure kinetics of the resin system. The final shrinkage of the

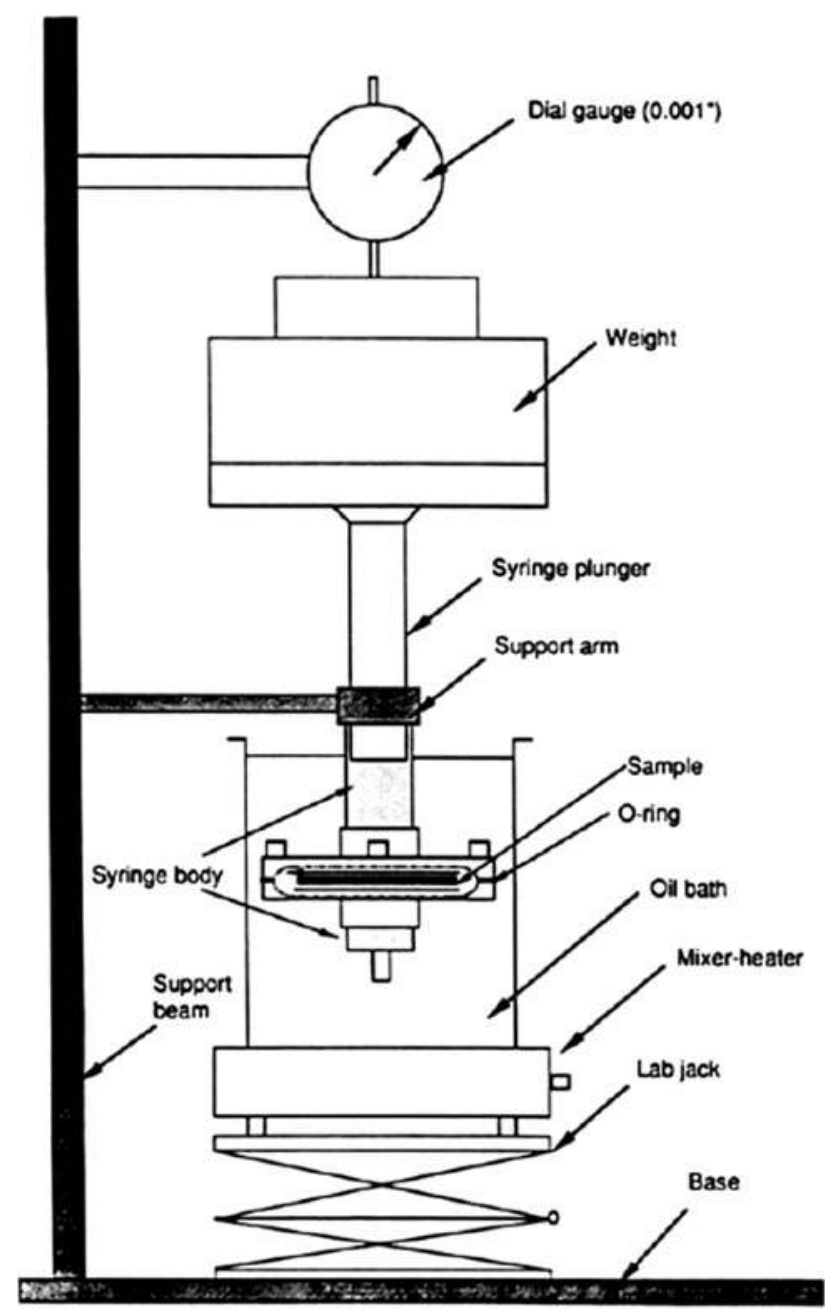

Fig. 8 Schematic of glass syringe dilatometer [37] epoxy resin was plotted versus (\%) degree of cure (Fig. 7). Authors found that shrinkage curve was bilinear, with a break point at about gel point ( $30 \%$ of cure) of resin used. They suggested that upon gelation the cure shrinkage was hindered by the build-up of 3D network of polymer chains, resulting in low rate of volumetric change with crosslinking. Two curves were fitted to find the shrinkage equation. The final shrinkage was found equal to $6.9 \%$.

Low pressure conditions, isothermal curing, use of another instrument for degree of cure measurement are the limitations of this technique.

\section{Plunger (PVT)-type dilatometer}

This type of device can be compared to a syringe which contains and pressurize the sample. The plunger of the syringe is monitored to follow the volume changes. Many authors [21, 31-36] used this instrument for the dilatometry on thermoset resins. Some commonly known PVT devices are described below:

Kinkelaar's PVT Kinkelaar and Lee [37] developed many versions of PVT instruments. In 1992, he presented a low pressure and low temperature dilatometer. The heating and cooling methods were not sophisticated and control of the temperature was difficult. The instrument was used to study UPE (unsaturated polyester resin) with LPA (low profile additives) at $80^{\circ} \mathrm{C}$ at pressure of $0.35 \mathrm{MPa}$. The sample was sealed (air-free) in a PE pouch and was placed between two screens, in a cavity made in two aluminium discs. A $30 \mathrm{ml}$ glass syringe was cut in half and glued into the holes, as shown in Fig. 8. Two thermocouples were placed inside the sample and in the dilatometer cavity. The cavity was filled with silicon oil.

The pressure was applied by putting the weights on the syringe plunger. The movement of weights followed by
Fig. 9 Styrene polymerization [37]

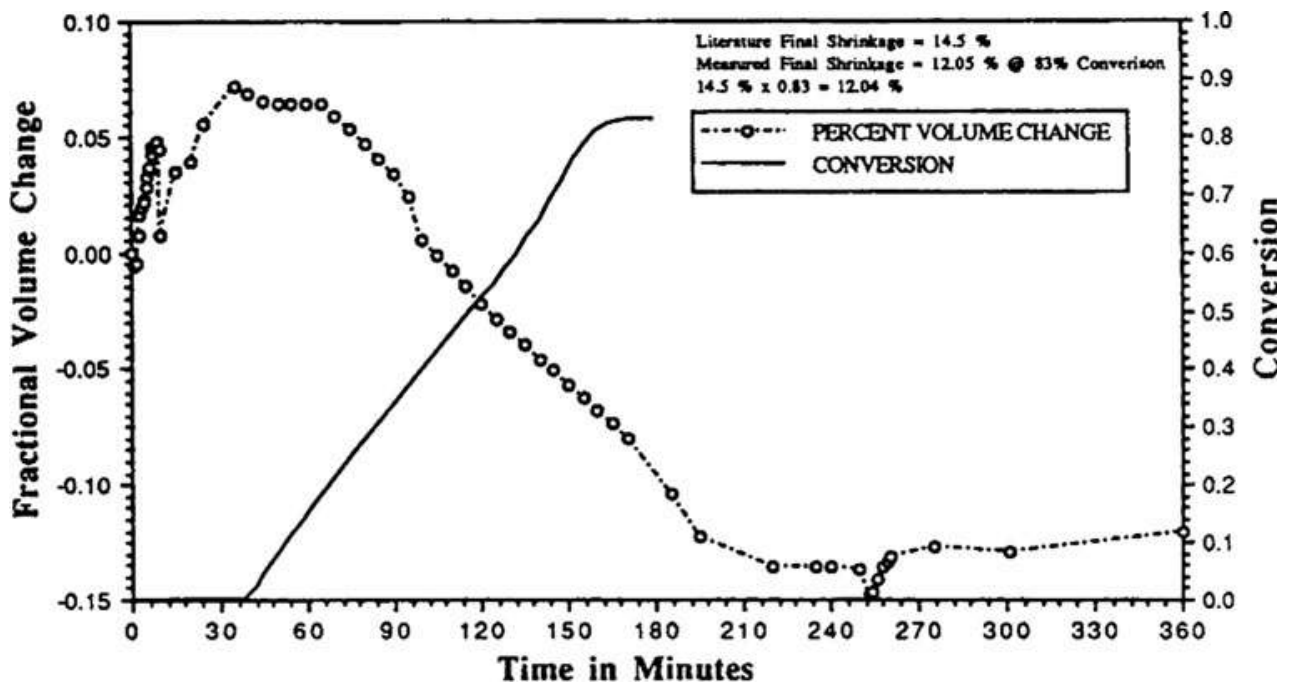


volume variation of resin gave the linear indication and was recorded by dial gauge or LVDT sensor. Portion of syringe containing sample was immersed in a heating bath mounted on support for heating. For cooling, the bath was replaced by a cooling box manually. Maximum temperature limit was found to be less than $90{ }^{\circ} \mathrm{C}$ as any larger heat produced could not be dissipated quickly causing boiling, bubbles in syringe.

Figure 9 shows the volume changes of styrene, cured following a specific curing cycle including heating ramps and finally isothermal curing at $80{ }^{\circ} \mathrm{C}$ as a function of time and degree of cure. Evolution of the degree of cure was found using differential scanning calorimeter following the same temperature profile as used in dilatometer. The final shrinkage of styrene at $80 \%$ degree of cure was found equal to $12.05 \%$. Low pressure, low temperature condition and inefficient heating and cooling system are the limitations of this system.

Later on, Kinkelaar and Lee [37] developed a high pressure and high temperature dilatometer instrument. An improved version of this instrument was also presented [38]. This instrument offered better temperature control, quicker heating and heat dissipation, higher pressure and temperature capabilities and easier use. A hydraulic cylinder that could withstand about $200{ }^{\circ} \mathrm{C}$ and $3.5 \mathrm{MPa}$ pressure was used instead of the glass syringe. The cavity dimensions and pouch material were the same as those of the glass syringe dilatometer. Heating was improved by welding heating coils in the high pressure unit. This dilatometer was constructed of copper to decrease the heating time.
Pressurization was done using silicon oil and an accumulator was used to prevent changes in pressure due to volume changes and to maintain a steady pressure. The $\mathrm{Sh}$ of unsaturated polyester resin was found equal to $6.5 \%$. Sample size limit for both dilatometers was $7 \pm 3 \mathrm{~g}$.

GNOMIX high pressure dilatometer GNOMIX dilatometer is a high pressure and high temperature dilatometer used by several authors for dilatometry of thermoset resins [39]. Mercury is used in this device as confining fluid. Toxicity of mercury is a significant problem of such devices.

PVT- $\alpha$ mould This device (Fig. 10) gives information about degree of cure in addition to the volume variation [22, $40,41]$ and has been used to study the neat thermosetting resin and composites(several millimetre thick and $40 \mathrm{~mm}$ diameter) under an adjustable pressure up to $10 \mathrm{MPa}$ and temperature up to $200{ }^{\circ} \mathrm{C}$. The heating is ensured by three heaters located at the top and bottom to heat the piston and cavity, respectively. More details about this device are given in [41, 42]. Two heat flux sensors [43] placed in the bottom of the mould and in the piston provides information on surface temperature of sample and heat flux density.

The movement of piston following the volume variations are recorded by LVDT-type displacement sensor with a precision of $1 \mu \mathrm{m}$ and a limit of $10 \mathrm{~mm}$. Boyard et al. [42] used this instrument to identify dilatometric behaviour of BMC material during cure. This material was based on unsaturated polyester prepolymer and a thermoplastic low

Fig. 10 PVT- $\alpha$ mould

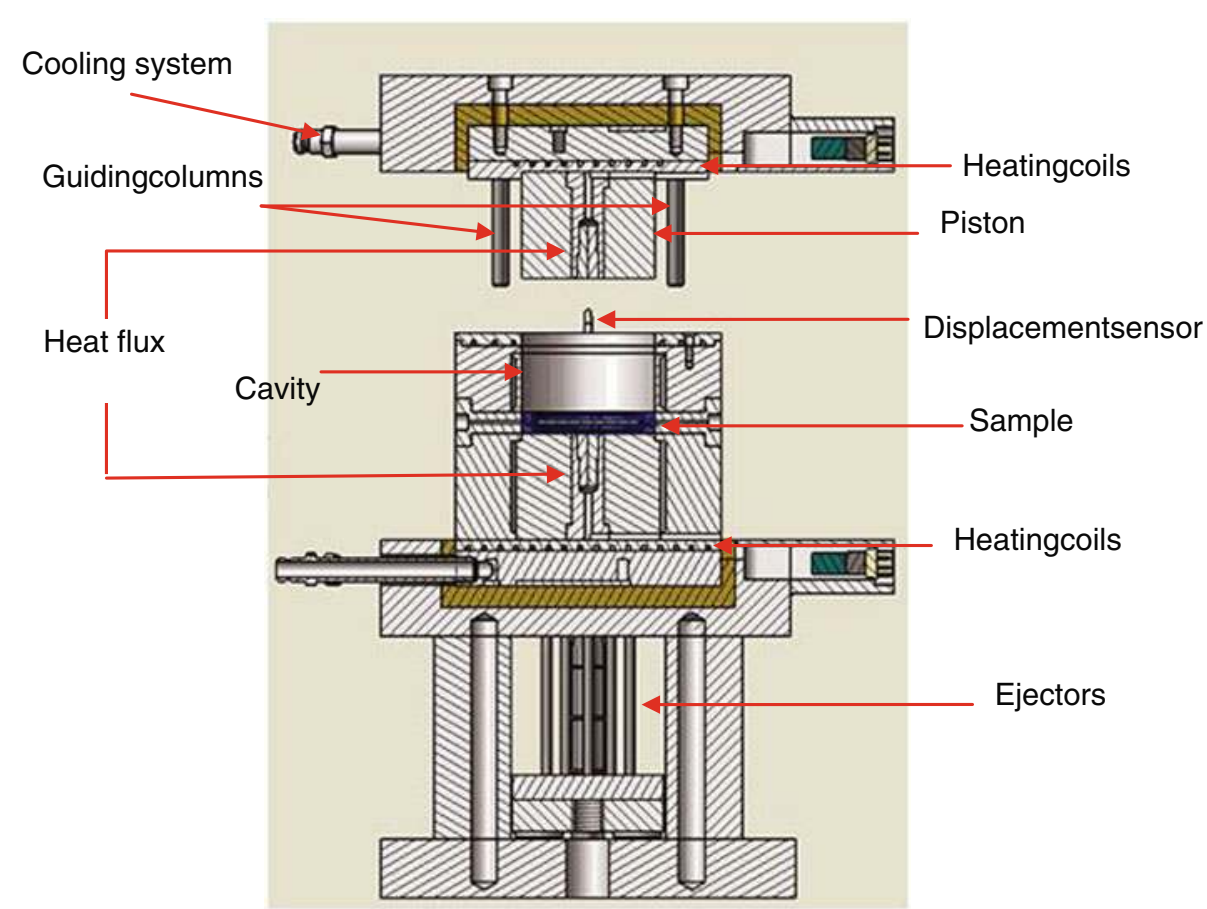


profile additive (LPA) as shrinkage compensation agent. The cycle started at $40{ }^{\circ} \mathrm{C}$ (for $15 \mathrm{~min}$ ). Then temperature was increased linearly to $180{ }^{\circ} \mathrm{C}$ at $5^{\circ} \mathrm{C} / \mathrm{min}$ and was maintained for $15 \mathrm{~min}$ followed by cooling to $40^{\circ} \mathrm{C}$. Figure $3 \mathrm{~b}$ shows the thickness and temperature variation during the cycle. An increase in thickness in the beginning corresponds to T.E and then a quick fall indicates the Sh. The shrinkage was found as a linear function of degree of cure. A shrinkage model demonstrated the effect of LPA to compensate the shrinkage.

Nawab et al. [24] determined volume Sh of vinylester resin considering the thermal gradients. While modelling, Sh was considered linear for a volume element. But global behaviour of shrinkage versus degree of cure was found nonlinear (Fig. 11). They also studied the effect of fibre volume fraction on volume Sh of these composite. In another study [44], they used this instrument in dynamic pressure and measured the Sh of vinylester resin. This instrument was also provided with an optical sensor to measure Sh along with different optical properties of RTM6 resin [45].

Plunger-type dilatometers provide a dilatometric measurement for the whole curing process and are able to work under industrial (high pressure and high temperature) conditions.

In plunger-type dilatometer, a certain amount of pressure is required to apply for the resin during the test. This may affect the shrinkage behaviour of resin. Furthermore, resin is contained in a non-reactive pouch. The exact behaviour of this material is very difficult to determine since properties of resin are changing continuously during the curing. This may also affect the quality of the results.

Non-volume dilatometric methods

In such techniques, shrinkage measurements are obtained by means of a contacting or non-contacting transducer.

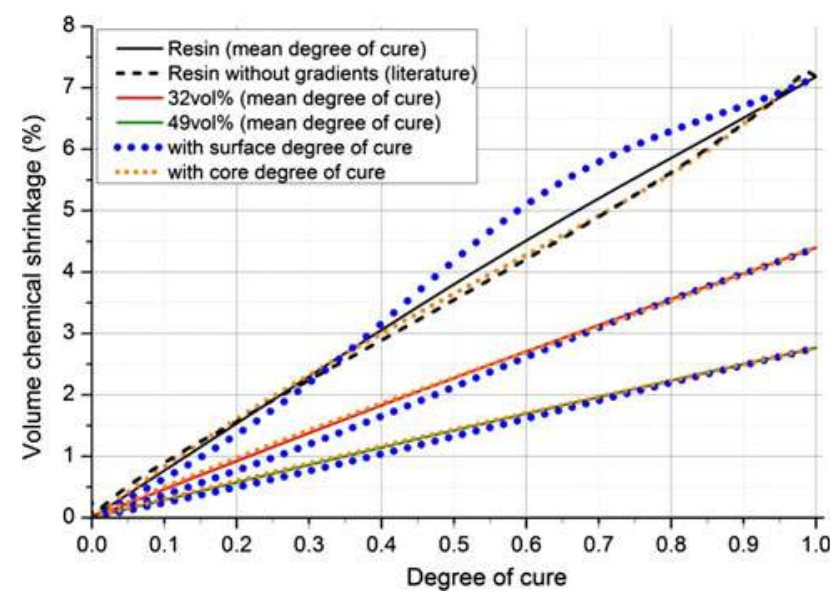

Fig. 11 Chemical shrinkage versus degree of cure of vinylester resin and associated composites [24]
Some of these techniques are described briefly in the following subsections:

\section{From density variation}

Resin shrinkage during curing causes a change in its density. Therefore, density variation was also taken as an indicator of Sh in some studies.

ASTM D2566 [17] used by Bucknall et al. [46] to determine the apparent linear shrinkage of resin during curing. This method also suggests using variation of density during curing for determination of Sh. On subtracting the T.E, determined using coefficients of T.E, from total shrinkage, Sh is obtained.

An experimental setup [16, 47] for the shrinkage measurements of epoxy resin based on density change is shown in Fig. 12. The test procedure consisted of measuring the sample weight in air, then weighing the sample (2-3 g) while suspended on a holder and immersed in the inner bath of silicon oil. A balance was used to monitor and record on a personal computer the weight change of the sample during cure. The sample density was then deduced from this data. Using values of density of uncured resin $(\rho)$ and curing resin $(\rho 1)$ at a given temperature, volumetric shrinkage was found using Eq. 1:

Volumetric shrinkage $[\%]=\left(1-\frac{\rho 1}{\rho}\right) \times 100$

Chemical shrinkage of epoxy resin was found equal to $10 \%$, which is higher than other such values reported in literature.

Magniez et al. [48] used the same setup to find the apparent Sh of RTM6 resin. The silicon bath was replaced with a water bath. Five gram of resin sample was cured at isothermal temperature of $150{ }^{\circ} \mathrm{C}$. Apparent Sh of this resin was found equal to $3 \%$.

Gillespie and co-workers $[49,50]$ measured in situ the Sh of vinylester resin using a density gradient column

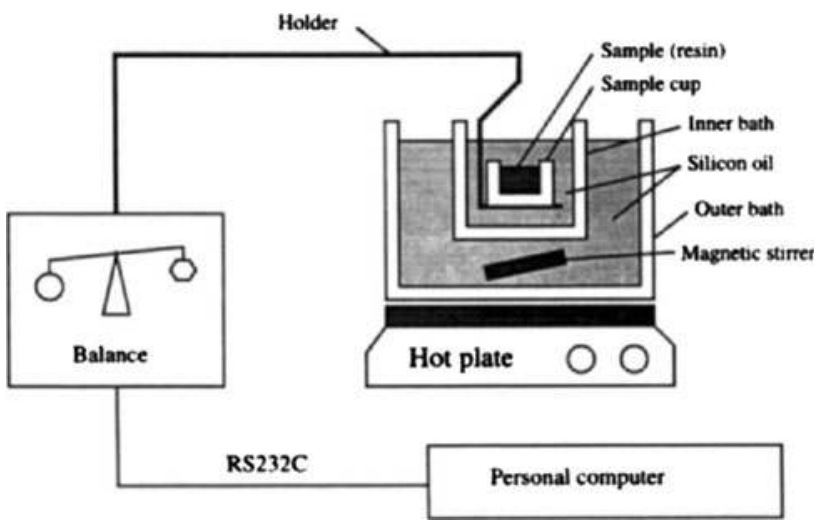

Fig. 12 Setup for the measurement of density variation during curing 
technique. A plaque of resin was cast under the desired isothermal condition $\left(30^{\circ} \mathrm{C}\right)$. After gelation, samples from the plaques were inserted into the column and density was monitored as a function of time. Sh was calculated from the density variation. Volume Sh of vinylester resin was found equal to $10 \%$.

\section{Dynamic mechanical analyser}

Lang et al. [51] and Schoch [52] used dynamic mechanical analysis (DMA) to monitor Sh. Schoch et al. [52] measured the shrinkage of amine-cured bisphenol A epoxy resin using a Rheometric Scientific RDA III DMA with an 8-mm diameter parallel plate fixture. Initial sample thickness was in about $0.5 \mathrm{~mm}$. This instrument adjusted the gap between parallel plates to maintain a fixed compressive or tensile load on the sample, while it was applying an oscillating shear displacement to one plate and measuring the torque on the other plate. Shrinkage was measured from the change of gap during the test and was found equal to $3.2 \%$. These results were then compared with pycnometer measurements (Fig. 13).

By DMA, the shrinkage of the resin can be monitored simultaneously with measurements of mechanical properties, i.e. viscosity, shear modulus, approximate gel time. In addition, experiment can be performed at elevated temperatures also.

\section{Thermal mechanical analyser}

TMA has been used by several authors for determination of Sh [53-55]. For example, Hong et al. [56] measured the cure shrinkage of epoxy resin using thermo mechanical analyser, and DSC. A very small amount of resin, less than $5 \mathrm{mg}$, having thickness less than $30 \mu \mathrm{m}$ was sandwiched between two silicon slides and placed on TMA sample platform (Fig. 14).

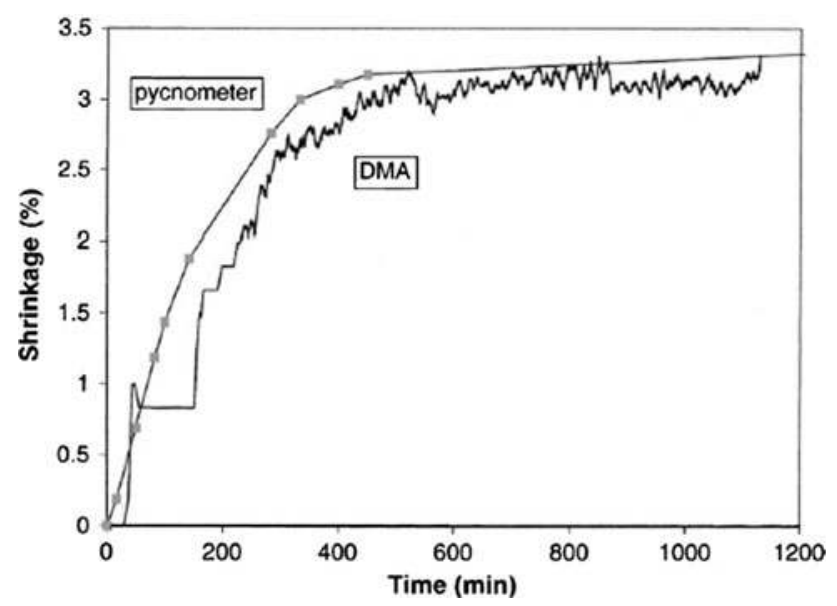

Fig. 13 Shrinkage curves by Pycnometer and DMA [52]

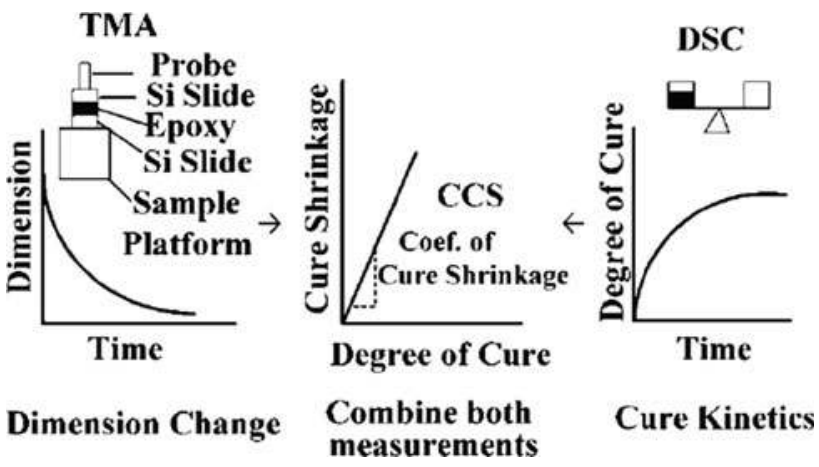

Fig. 14 Experimental procedure for characterization the cure shrinkage [56]

The measurement of dimension change was conducted at constant cure temperature. Then, the extent of conversion was monitored with DSC using the same temperature profile. By analysing curves of both instruments simultaneously, cure shrinkage was determined. It was found that Sh curve changed its slope from the gel point and reached a maximum shrinkage of $4 \%$.

Zarrelli et al. [57, 58] used TMA for the dilatometry of partially cured samples $(200 \times 400 \times 2.5 \mathrm{~mm})$ of epoxy resin. The testing gave the information on volume variation versus temperature, which later plotted versus degree of cure, determined by DSC. Figure 15 shows the dimensional changes of resin sample (initial degree of cure equal to 0.68 ) versus temperature. Deviation of curve from the linear behaviour (from $170{ }^{\circ} \mathrm{C}$ ) was supposed due to rubbery state of resin. An effect of Sh can be observed between 90 and $120{ }^{\circ} \mathrm{C}$. The liquid dilatometry was done in a home built dilatometer. The total shrinkage coefficient was found equal to 0.054 .

Yu et al. [59] used a similar setup, and measured Sh of NCA (non-conducting adhesive) thermosetting resin during an isothermal $\left(100^{\circ} \mathrm{C}\right)$ cure. Two types of resin NCA1 and

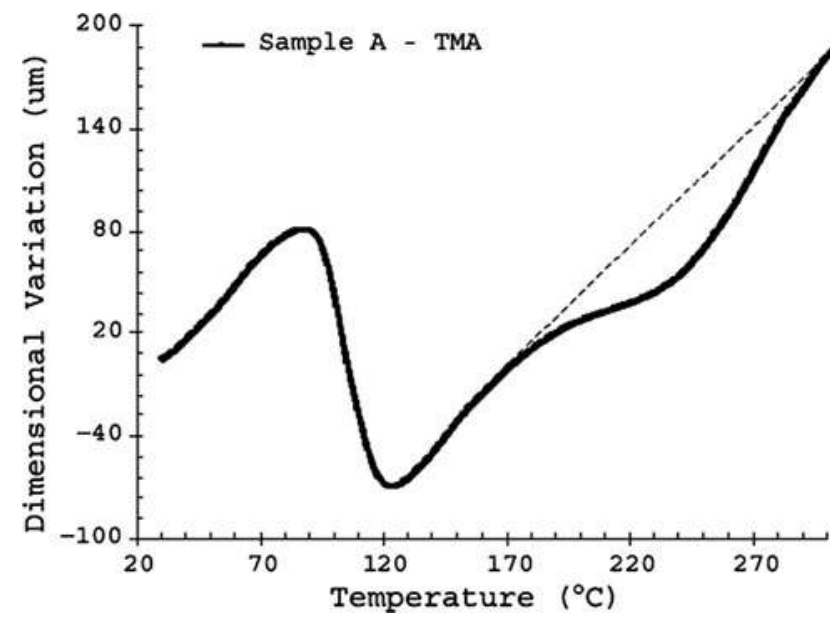

Fig. 15 Dimensional changes of epoxy sample during cure [56] 
NCA2 having gel points equal to 33 and $55 \%$ degree of cure, respectively, were investigated. It was found that shrinkage curve for both resin is bilinear and change its slope from gel point. Effect of applied load was also investigated. It was found that by increasing load, cure shrinkage decreases.

Testing of partially cured samples, use of DSC for determining degree of cure are the limitations of this technique.

\section{Rheometer}

Rheometer and DSC was used to measure the shrinkage of thermoset resin. For example, Haider et al. [60-62] developed a test procedure based on the rheometer normal force control (Fig. 16) to study the cure shrinkage of unsaturated polyester resin. The tests were performed under certain isothermal temperatures. It consisted of two segments: during the first one, when resin was in liquid state, the normal force kept zero with certain values of maximum angular strain and frequency, the distance between plates was kept constant. This segment continued
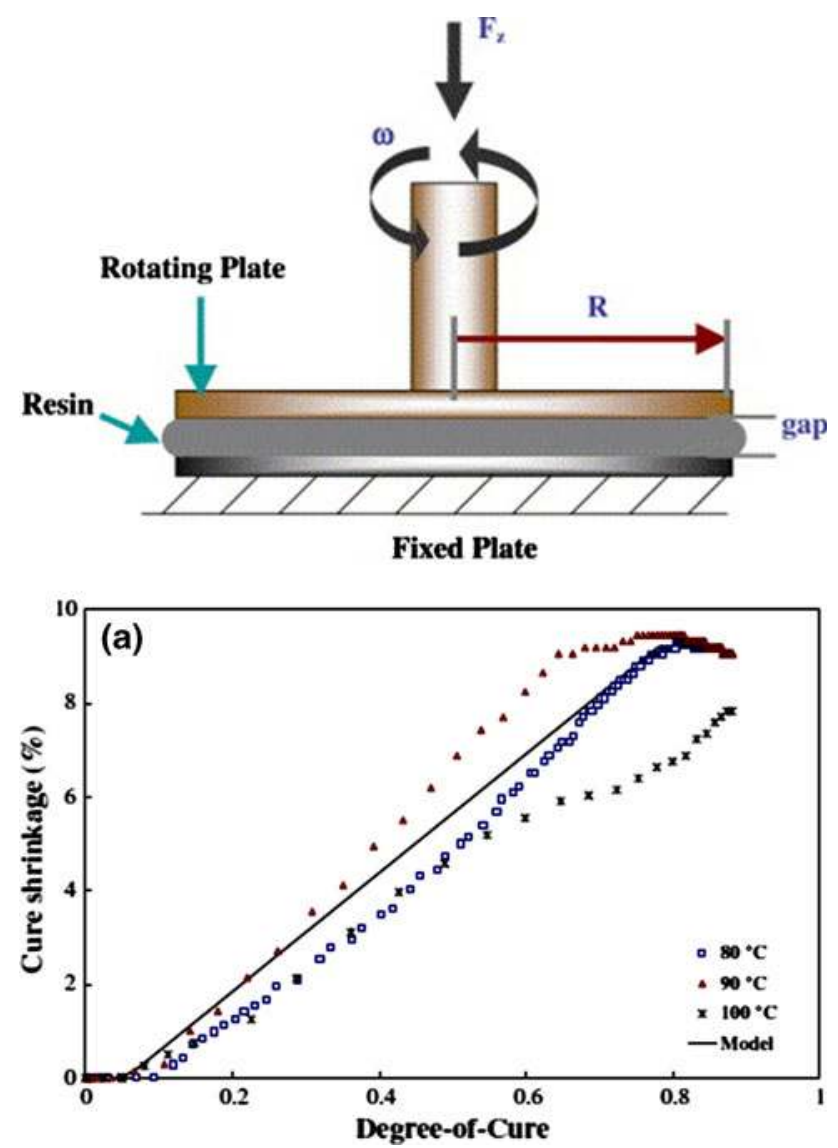

Fig. 16 Parallel plate geometry setup [60]. a Cure shrinkage as a function of degree of cure [60] till the beginning of Sh, identified by negative normal force.

In the second segment, frequency and torque increased with a constant normal force, i.e. $0.1 \mathrm{~N}$ but the gap might change. When the normal force was changed due to the expansion or shrinkage of resin, the gap changed also to compensate the change in normal force.

The gap change was converted to linear cure shrinkage, and from which volumetric cure shrinkage was found (Fig. 16a). No shrinkage was observed until gel point. But from there, a quasi linear was reported with a final shrinkage of about $9 \%$.

The non-volume dilatometry has a frequent problem: the contact between the resin and a solid surface such as the plates might induce stresses in the resin during cure. Therefore, it cannot precisely measure Sh of resin when it undergoes changes from a liquid to a rubbery and then to a glassy state. This problem also occurs in some volume dilatometers when the resin being measured is directly in contact with the container.

\section{Pycnometer}

Pycnometer, sometimes refers as gas pycnometer is a device for measuring volume of sample. It consists of two chambers as shown in Fig. 17: one for sample placement and the other is used as reference.

Both chambers are connected by a gas pathway having a valve. The pressure difference of gas, on filling the sample chamber and then evacuating it in the second chamber with and without sample, helps to compute the sample volume [61]. Various readings at regular intervals can give the volume as function of time.

Several authors used this method [52, 61, 63, 64] for Sh determination. The Fig. 18 shows the results obtained by Shah and Schubel [61] using pycnometer for unsaturated polyester resin. Segment 1a, 1b and III correspond the pregelation, post-gelation and post cure phases, respectively. The cure shrinkage of unsaturated polyester under ambient

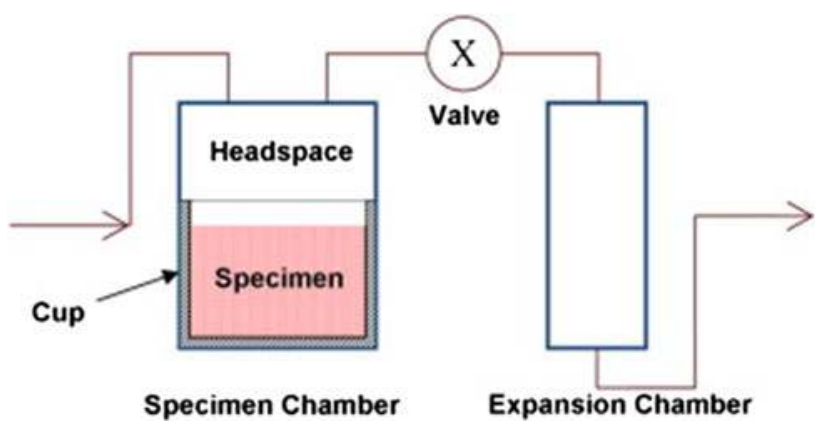

Fig. 17 Schematic of a pycnometer that uses a gas displacement technique [61] 
Fig. 18 Pycnometer test results for UP resin [61]

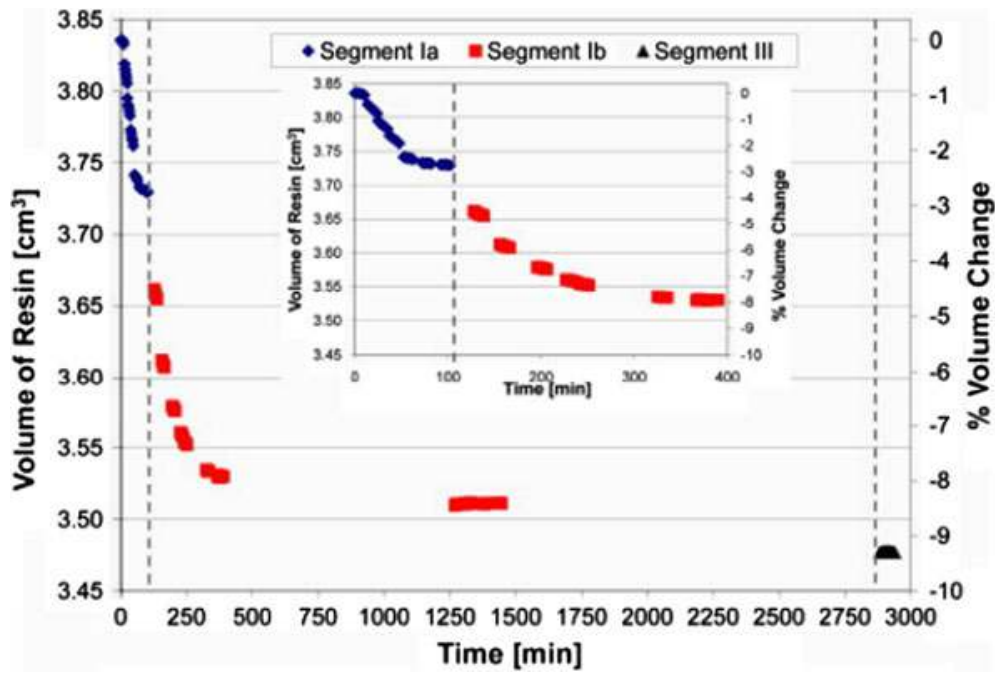

conditions was found to be $8.45 \%$ which increased to $9.10 \%$ after post-curing.

The disadvantage of this instrument is working only under ambient conditions. This instrument gives good results for the polymerization at low cure rate, small peak temperature and small thermal gradients. The exothermy of reaction may result in bad results.

\section{Using ultrasonic waves}

Hoa et al. [65] presented a method based on the measurement of the evolution of thickness of epoxy resin during cure, using the ultrasonic waves. The bulk modulus was also identified during this experiment.

The liquid resin sample was placed into a cup that had smooth surfaces inside and well-controlled dimensions. Liquid couplant was placed on top of the liquid resin sample. The couplant was selected such that it was less dense than the liquid resin and also chemically inert and immiscible with respect to the resin system.

The ultrasonic test cell (UT) was held fixed in the cup cover so that it was partially immersed in the liquid couplant (Fig. 19). The cup was set up so that it was in a horizontal position, i.e. the cup bottom was parallel to the liquid interface between the couplant and the resin. The test cell can be placed inside a thermo-regulated bath as required.

The principle of technique is based on the measurement of speed of sound of waves and time required to pass through the liquid couplant, placed on top of resin. Volume (corresponding to the thickness) of resin was obtained by treating the information about velocity of sound through the couplant and the time taken by sound for a round trip from UT to resin/couplant interface. Thickness of couplant (between transducer and resin/couplant interface), hence time required to pass through it, increases with shrinkage of

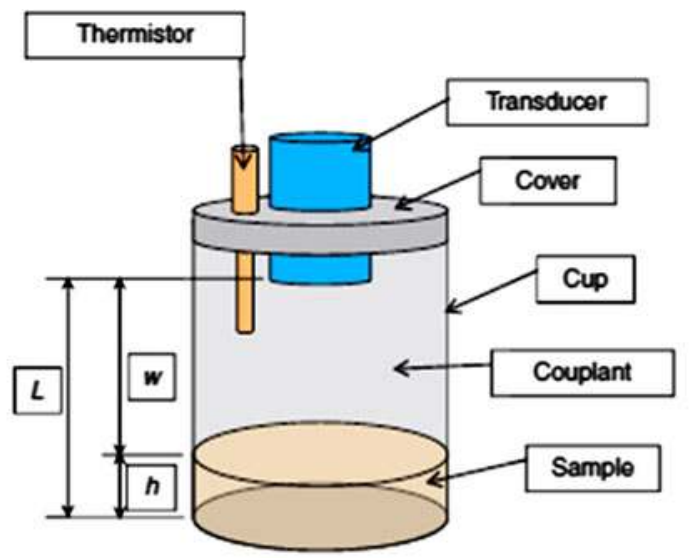

Figure 1. Schematic of PSM test cell.

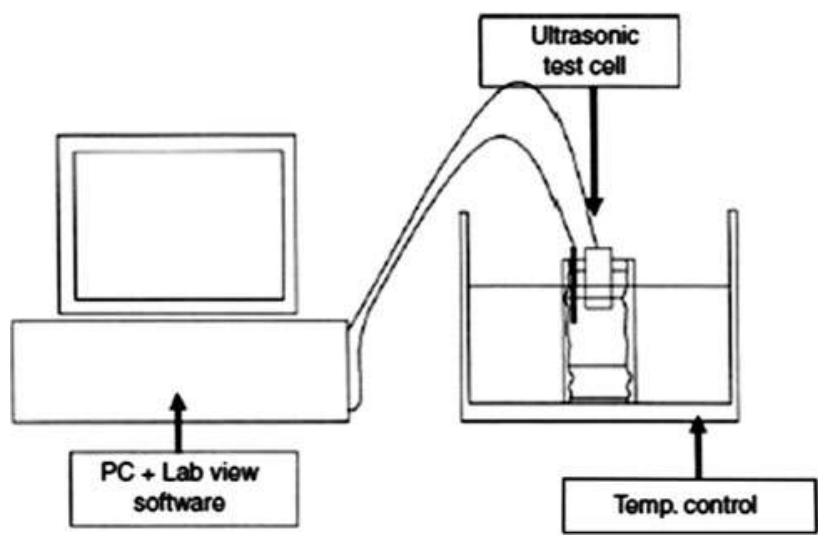

Fig. 19 Schematic view of the PSM instrumentation setup [65]

resin. Temperature of the system was also recorded during the experiment. Measurements by this setup were continuous. First reading of the system was too delayed so there are risks of error in measurement. Figure 20 shows the volume Sh of resin as function of time which ranges between 3 and $4 \%$ for various ratios of hardener. 


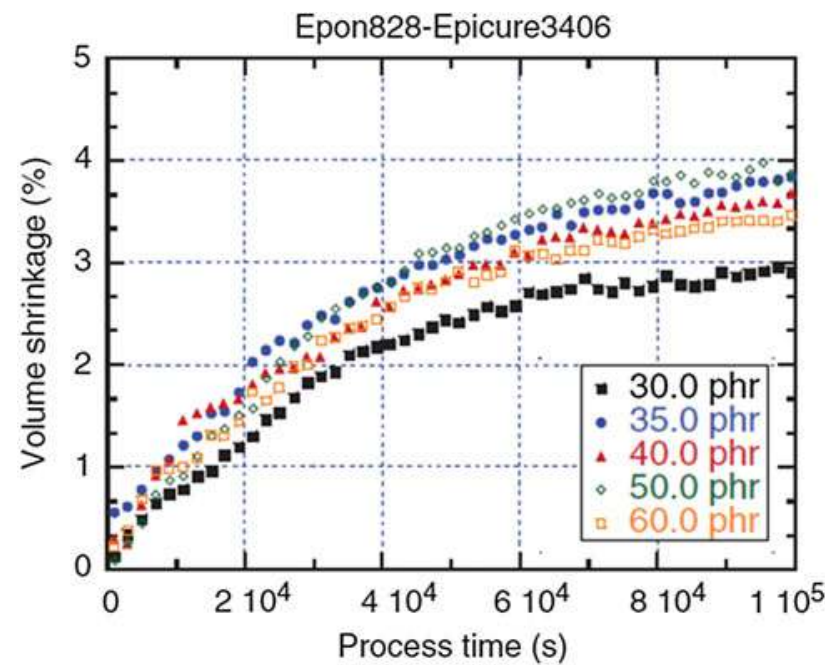

Fig. 20 Volume shrinkage $\%$ of resin for different amount of hardener [65]

Such experimental method may face the measurement problems, such as the non-uniform thickness of resin due to sticking with walls of container, and evaporation of couplant in which ultrasonic transducer (UT) is immersed. In the above presented study, container with very smooth inner surface was used to avoid sticking. Furthermore, sufficient quantity of couplant was used so that UT remained immersed in couplant throughout the test.

\section{Fibre Bragg gratings}

Fibre Bragg gratings (FBG) were used by several authors [66-73] for the Sh identification.

A schematic illustration of a FBG sensor is shown in Fig. 21a. The uniform FBG is a segment of optical fibre with a periodic modulation of the core refractive index. Usually, an in-fibre FBG can be fabricated on a photosensitive (germanium-doped or hydrogen-soaked) singlemode optical fibre using a UV laser source at 240-248 nm.

Basically, the principle of the FBG sensor is based on the measurement of the changes in reflective signal, which is the centre wavelength of back-reflected light from a Bragg grating, and depends on the effective refractive index of the core and the periodicity of the grating. According to the Bragg condition, the Bragg wavelength $\left(\lambda_{\mathrm{B}}\right)$ can be expressed as 2 times of the product of grating periodic spacing $(\Lambda)$ and the effective refractive index of the fibre core $n_{\text {eff }}$ [74]. So the Bragg wavelength will shift with changes in either $n_{\text {eff }}$ or $\Lambda$. When an external mechanical or thermal deformation is imposed on the grating area, the effective refractive index will be changed as well as the periodic spacing.

For example, Parlevliet et al. [66] used FBG to calculate polymer shrinkage/strain of a mixture of unsaturated polyester (Turane) and polyurethane resin during cure and after curing. Glass cylinders were coated with wax to avoid sticking of resin with the walls.

A simple guiding system was placed on top of the cylinder to ensure that the optical fibre was suspended in the centre of the cylinder (Fig. 21b). A K-type thermocouple was carefully positioned close to the gratings for the temperature measurements. After mixing and degassing, the resin was gently poured into the test tubes and allowed to cure. Heating was done with a hot oil bath, in which setup tube was suspended. Gel point of resin system was determined successfully equal to $40{ }^{\circ} \mathrm{C}$ (point $\mathrm{A}$ in Fig. 21c). The resultant curing strain is presented in Fig. 21c as function of temperature. The linear Sh was found equal to $1.9 \%$. Sticking of resin with container walls, lack of control of resin temperature are the apparent limitations of this system. Moreover, the presence of thermocouple and sensor within the resin sample may induce additional stresses and may affect the final results.

\section{Laser beam scanning method}

Thomas and Bur [75] measured the dimension change of polystyrene during cure by embedding the optical sensors. Using a helium-neon laser (wavelength, $632.8 \mathrm{~nm}$ ) light source, the sensor was used to detect light reflections from the interfaces in the resin filled mould. A scheme of setup is shown in Fig. 22a.

On shrinkage, the resin separates from the sapphire window or the opposite wall creating a gap between resin and window (or wall). The separation of the mould and polymer surfaces is detected by an abrupt increase in reflected light: this is followed by interference fringes which develop via interfering reflections from the sapphire window and the receding polymer resin surface. By counting fringes as a function of time, shrinkage and rate of shrinkage of the resin product were measured.

From the laser reflections they detected the Sh of sample, which is plotted versus curing time in Fig. 22b.

Fano et al. [76] used a similar method for measurement of Sh of dental materials.

\section{Strain gauge method}

The strain gauges have been used since many years for the displacement measurement due to applied external or internal load for conventional materials. Some authors [77, 78] extended their use for the measurement of cure shrinkage of thermoset matrix also.

For example, Ochi et al. [77] cured epoxy resin in a silicon rubber mould. A steel ring bonded by a strain gauge (KFC-10-C-1-11, Kyowa Electric Co., Ltd.) was placed in the mould containing resin. Curing caused the production of Sh strain and stress on the ring, which was measured by the 
Fig. 21 a A schematic illustration of an FBG sensor. b Schematic view of matrix shrinkage test set-up [66]. c Strain development with temperature during cure of UP [66] (a)
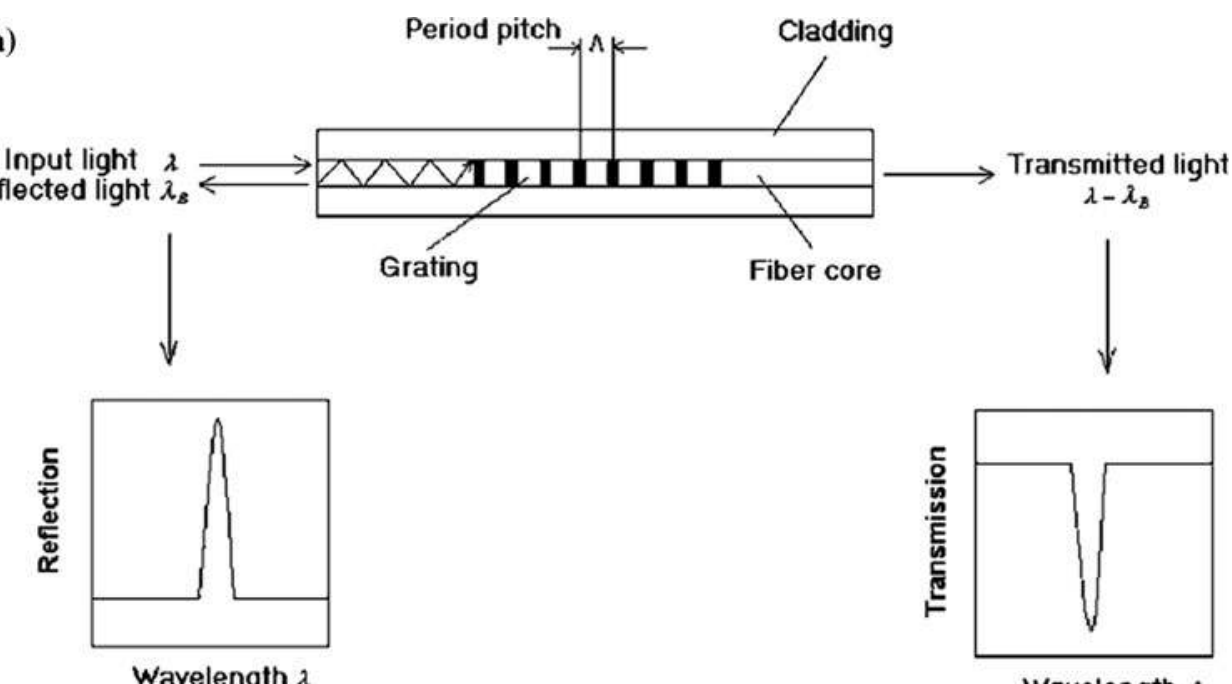

Wavelength $\lambda$

(b)

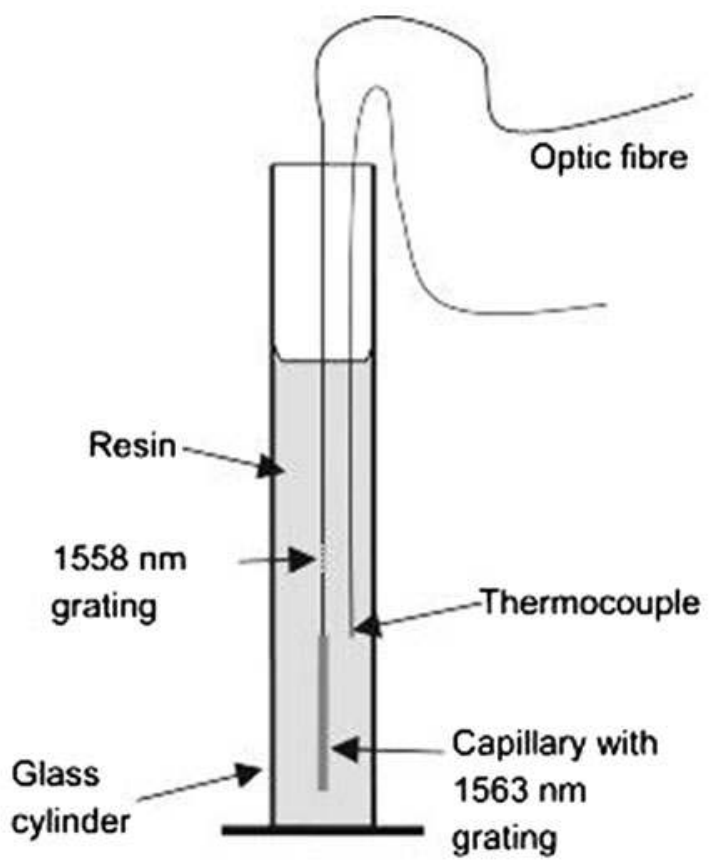

(c)

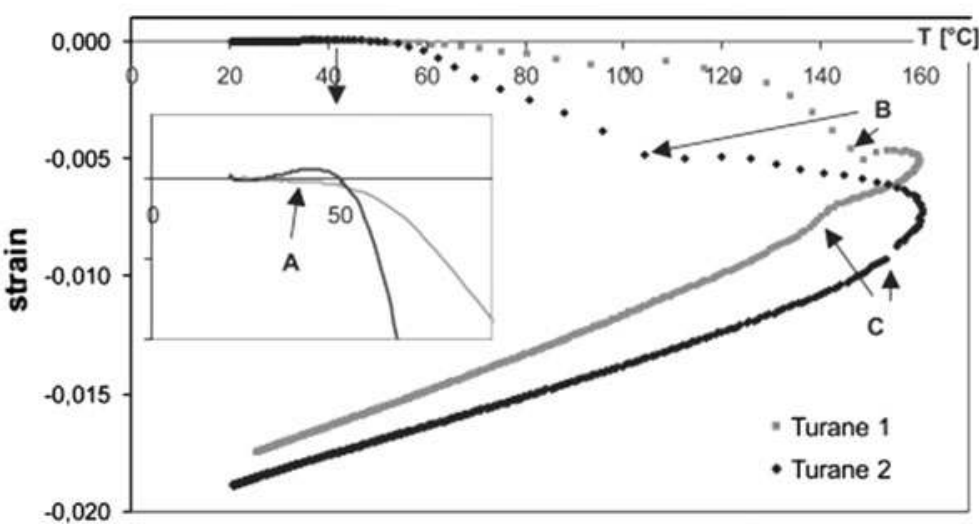


Fig. 22 a Scheme of measurement setup b chemical shrinkage versus curing time [75]
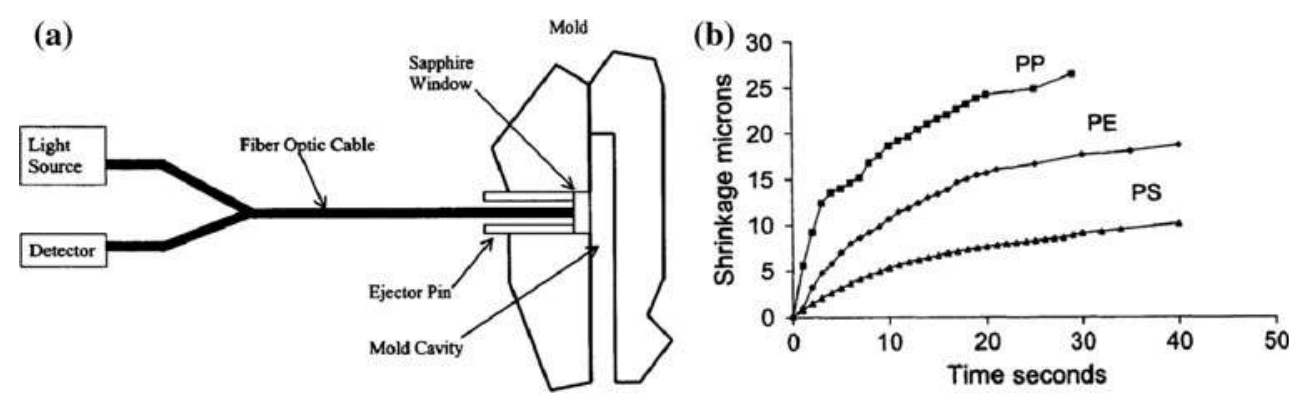

Fig. 23 a chemical shrinkage versus curing time of four different epoxy resin $\mathbf{b}$ scheme of measurement setup
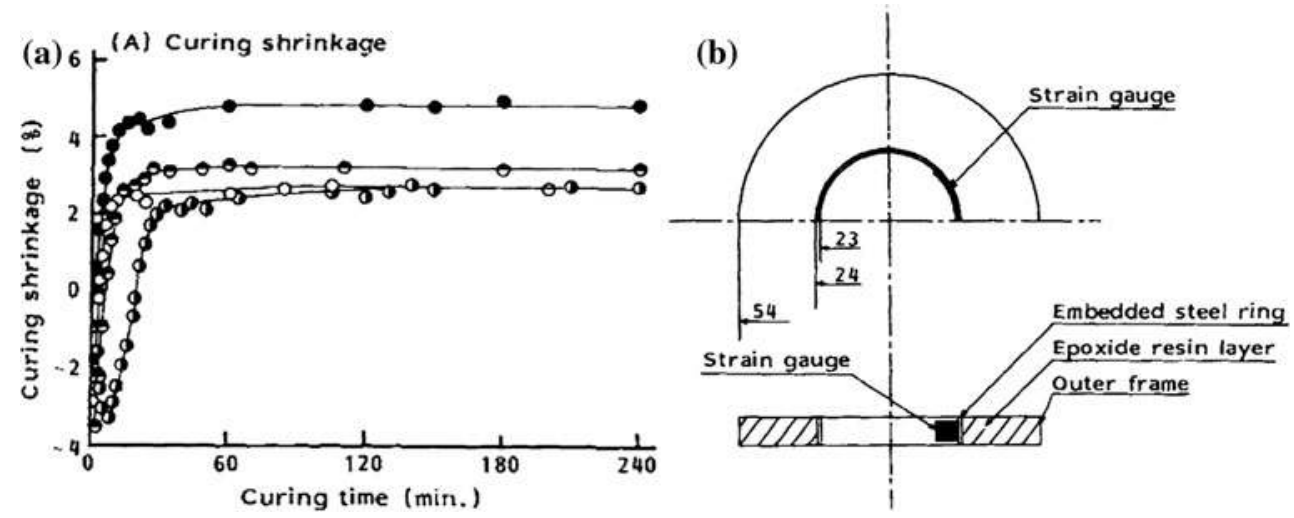

strain gauge. The measurement setup is shown in Fig. 23b. The results of Sh of two different epoxy resins versus curing time are shown in Fig. 23a. Use of strain gauges is a reliable method of Sh determination. The limitations are low pressure measurement. Moreover, the presence of external object in matrix can affect its shrinkage behaviour.

\section{Miscellaneous techniques}

These techniques are often used for the measurement of Sh of dental materials. For example, Sun et al. [79] measured the Sh using X-rays analysis. Sharp et al. [80] measured the Sh by video imaging.

A summary of techniques used for dilatometry of thermoset matrix along with resin system, sample size, temperature and pressure conditions, and respective limitations/advantages is given in Table 1.

\section{Sh determination techniques for composites}

Not many studies are conducted on the determination of Sh of composite. A summary of techniques used for this purpose is presented in Fig. 24.

\section{Volume Sh of composites}

Studies for determination of volume Sh of composites are found rarely.
Plunger-type dilatometer

The device and working principle are described in the preceding section. This setup has also been used for dilatometry of composites. For example, Russell [81] used GNOMIX PVT device for determination of global volume Sh of UD laminated (carbon/epoxy) composite. 1-2 g composite samples with [0], and [0/90] stacking sequences were studied. An example of variation of specific volume versus curing time for the given temperature cycle are plotted in Fig. 25. A pressure of $10 \mathrm{MPa}$ was maintained throughout the test to avoid evaporation of mercury. The determined shrinkage was related to the development of mechanical properties of composite.

Problems faced were the toxicity of sample confining fluid (mercury), voids in the sample and inaccurate determination of degree of cure.

Same device was also used to study the epoxy moulding compound with and without fillers [82]. They also studied the effect of fibre volume fraction on volume Sh of these composite. Though not found the same by experiments (Fig. 26), they assumed the Sh linear versus degree of cure. Millischer and Delaunay [83] studied the behaviour of bulk moulding compound in mould PVT- $\alpha$. Nawab et al. [24] determined volume Sh of $6 \mathrm{~mm}$ thick and $41 \mathrm{~cm}$ diameter glass/vinylester composite considering the thermal gradients (Fig. 11). Results suggest that thermal gradients have no significant effect on evolution and quantity of volume Sh of composites due to the presence of low amount of 
Table 1 Summary of techniques used for dilatometry of thermoset resin

\begin{tabular}{|c|c|c|c|c|c|c|}
\hline Category & Technique & Resin & Sample size & $\begin{array}{l}\text { Pressure } \\
(\mathrm{MPa})\end{array}$ & $\begin{array}{l}T\left({ }^{\circ} \mathrm{C}\right) \text { up } \\
\text { to }\end{array}$ & Comments \\
\hline \multirow[t]{5}{*}{ Volume } & $\begin{array}{l}\text { Capillary } \\
\text { type }\end{array}$ & VE, Ep & $1-100 \mathrm{~g}$ & Atm & $\begin{array}{l}\text { Isothermal } \\
(200)\end{array}$ & $\begin{array}{l}\text { Sticking of resin with walls, manual reading and isothermal } \\
\text { and low pressure cure. }\end{array}$ \\
\hline & $\begin{array}{l}\text { Gravimetric } \\
\text { method }\end{array}$ & Ep & $3.7 \mathrm{~g}$ & Atm & $\begin{array}{l}\text { Isothermal } \\
\text { (110) }\end{array}$ & Low pressure, use of another instrument for degree of cure \\
\hline & $\begin{array}{l}\text { PVT- } \alpha \\
\text { mould }\end{array}$ & $\begin{array}{l}\text { VE, } \\
\text { UP, } \\
\text { Ep }\end{array}$ & $10 \mathrm{~g}$ & Up to 10 & 400 & $\begin{array}{l}\text { High pressure, temperature condition and measures heat flux } \\
\text { (degree of cure) in the same experiment. Cannot work at } \\
\text { atmospheric pressure. }\end{array}$ \\
\hline & $\begin{array}{l}\text { Low } \\
\text { pressure } \\
\text { plunger } \\
\text { type }\end{array}$ & Styrene & $7 \pm 3 \mathrm{~g}$ & 0.35 & 90 & $\begin{array}{l}\text { Low pressure and temperature conditions, inefficient heating } \\
\text { and cooling system, use of DSC for degree of cure. }\end{array}$ \\
\hline & $\begin{array}{l}\text { High } \\
\text { pressure } \\
\text { plunger } \\
\text { type }\end{array}$ & UP & $7 \pm 3 \mathrm{~g}$ & 3.5 & 204 & $\begin{array}{l}\text { High pressure and temperature conditions, use of DSC for } \\
\text { degree of cure is required. }\end{array}$ \\
\hline \multirow[t]{7}{*}{$\begin{array}{l}\text { Non- } \\
\text { Volume }\end{array}$} & $\begin{array}{l}\text { Density } \\
\text { variation }\end{array}$ & VE & $5 \mathrm{~g}$ & Atm & $\begin{array}{l}\text { Isothermal } \\
\text { (170) }\end{array}$ & $\begin{array}{l}\text { Simple method. Low pressure and isothermal cure only. Use } \\
\text { of DSC for degree of cure is required. }\end{array}$ \\
\hline & DMA & Ep & $0.5 \mathrm{~mm}$ thick & Atm & 200 & $\begin{array}{l}\text { Very small sample, used DSC for degree of cure, } \\
\text { measurements after gel point }\end{array}$ \\
\hline & TMA & Ep & & Atm & 120 & $\begin{array}{l}\text { Dilatometry of partially cured samples, used DSC for degree } \\
\text { of cure measurement }\end{array}$ \\
\hline & Rheometer & UP & $0.5 \mathrm{~mm}$ thick & 0.1 & 120 & $\begin{array}{l}\text { Small sample size, isothermal, low pressure conditions, } \\
\text { change of experimental condition before and after gel } \\
\text { point. }\end{array}$ \\
\hline & Pycnometer & UP & $0.005 \mathrm{~cm}^{3}$ & Atm & $\begin{array}{l}\text { Isothermal } \\
\text { (RT) }\end{array}$ & Low cure rates, low temperature, low thermal gradients \\
\hline & $\begin{array}{l}\text { Fibre Bragg } \\
\text { gratings }\end{array}$ & UP & $10 \times 3 \times 3 \mathrm{~mm}^{3}$ & Atm & 205 & $\begin{array}{l}\text { Low pressure, need of DSC for degree of cure, the presence } \\
\text { of thermocouples and sensors within sample. }\end{array}$ \\
\hline & $\begin{array}{l}\text { Ultrasonic } \\
\text { waves }\end{array}$ & Ep & $20 \mathrm{~g}$ & Atm & $\begin{array}{l}\text { Isothermal } \\
\text { (RT) }\end{array}$ & Isothermal and low pressure conditions. \\
\hline
\end{tabular}

$V E$ vinylester, Ep epoxy, $U P$ unsaturated polyester, Atm atmospheric pressure, $R T$ room temperature

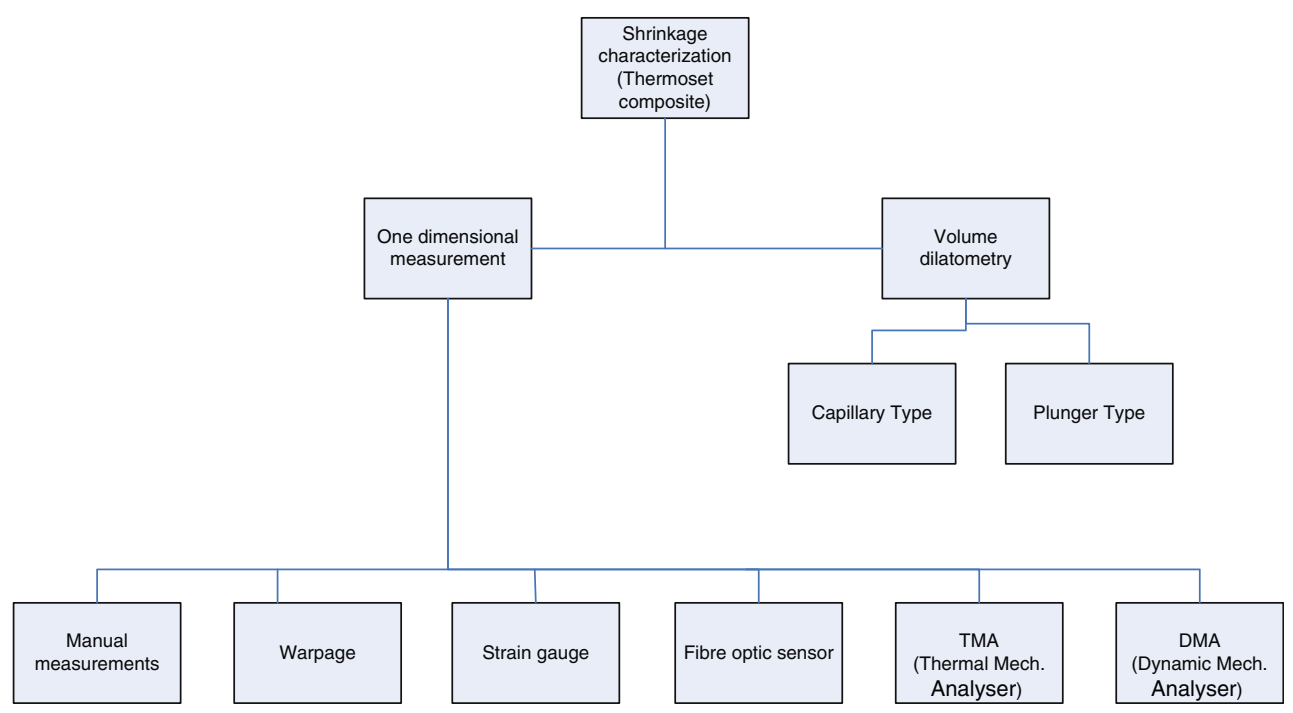

Fig. 24 Chemical shrinkage techniques for composites 


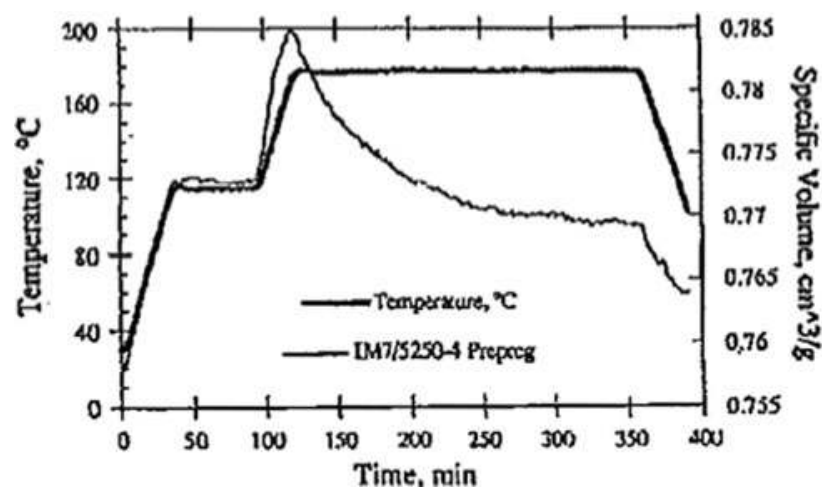

Fig. 25 Specific volume variation of carbon/epoxy laminate composite [81]

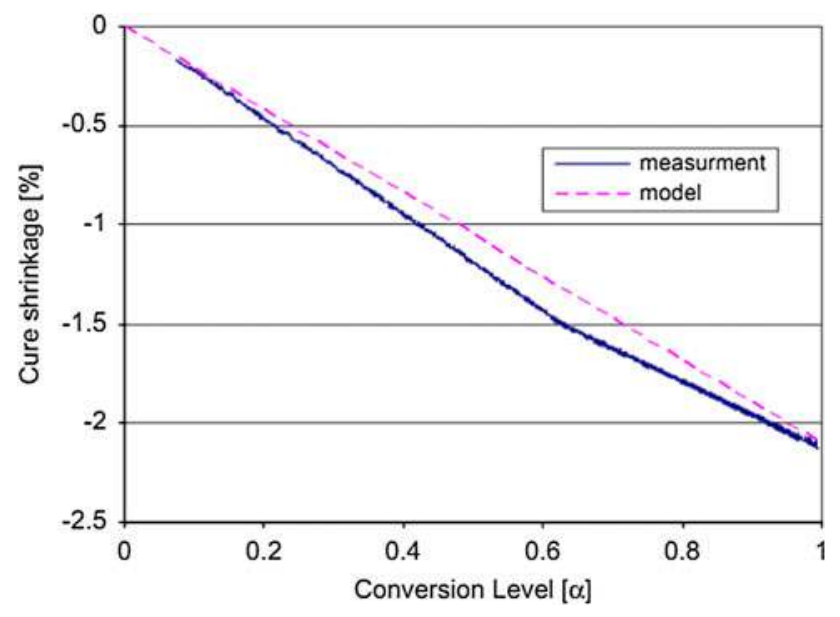

Fig. 26 Chemical shrinkage versus degree of cure [82]

resin. They reported that fibres block the Sh of resin which remains in the composite in the form of residual stress. Volume Sh of glass/vinylester cross-ply composite with 32 and $49 \%$ fibre volume fraction was found linear, and equal to 4.4 and $2.8 \%$, respectively.

Prasatya et al. [84] measured Sh of a thermosetting polymer Hexcel 8551-7 using a pressurisable bellows dilatometer for an isothermal cure at $122{ }^{\circ} \mathrm{C}$ and $5 \mathrm{MPa}$. It is a general practice to use mercury which is highly toxic as the fluid in dilatometers of this type. The direct contact with fluid may also affect the cure of the resin systems in the test.

\section{Capillary-type (laser scanning) dilatometer}

Holst et al. [85] determined the volume Sh of epoxy system containing fillers using a laser scanning dilatometer.

A scheme of setup is shown in Fig. 27a. Tests were conducted on neat epoxy resin and filled with different percentages of $\mathrm{CaCO}_{3}$. The sample was placed in a glass tube below silicon oil. The position of the upper and/or lower edge of the relevant resin meniscus was detected by the laser (a)

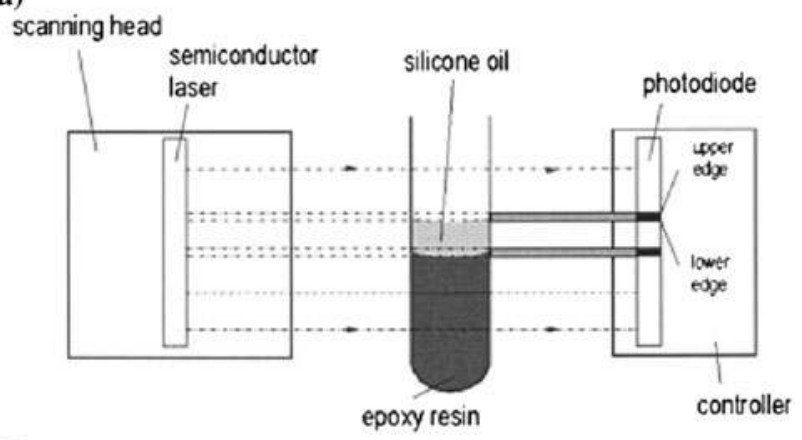

(b)

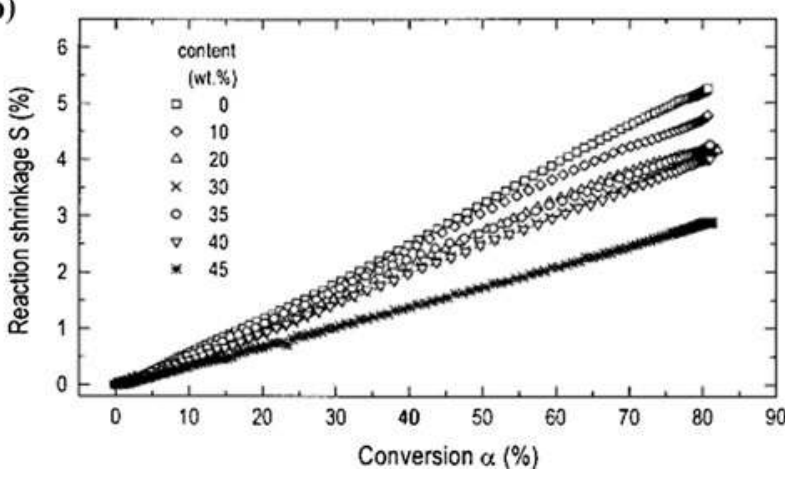

Fig. 27 a Chemical shrinkage versus degree of cure [85]. b Chemical shrinkage versus degree of cure

scanner. From the change in the sample height, the sample volume for a given time was calculated after a volume calibration of the glass tube. Volume Sh calculated from the volume variations are plotted versus degree of cure in Fig. 27b. Degree of cure was determined using DSC. It can be noted that volume shrinkage versus degree of cure $(\alpha)$ is linear for neat resin and for that filled with $\mathrm{CaCO}_{3}$.

Normalized volume Sh results suggested that presence of filler has blocked the shrinkage.

Use of laser assured précised measurement of volume but sticking of sample with the walls of container, creation of cracks or other cavities in the sample during the measurement are the drawbacks that may lead to erroneous results. Moreover, measurements under atmospheric pressure and isothermal conditions are the limitation of this technique.

Linear Sh of composites

Some authors also carried out to find the linear Sh and resultant strain in composites. Measurement principals, significant results, and advantages and drawbacks of these techniques are given briefly below:

\section{Manual measurement at regular intervals}

White and Hahn [86] studied Sh of a single ply of bismaleimide matrix composite using a very simple method. 
The plies were cut to $25.4 \times 152 \mathrm{~mm}$ with the transverse direction along the $152 \mathrm{~mm}$ length of the strip. Six prepreg plies were placed on an aluminium caul plate with release plies (Teflon) between the specimens and the caul plate so that each specimen was allowed to shrink with minimal constraint. These specimens were then cured in an oven. At each of the predetermined points during the cure cycle, a single specimen was removed and allowed to cool to room temperature. Specimen dimensions were taken after several minutes at room temperature. The chemical strains were then calculated from changes in specimen dimensions at room temperature. The authors suggested that the chemical strains were large in magnitude, but they were experienced very early in the cure cycle when the mechanical properties were quite low and creep response was significant. The Sh strains are plotted versus degree of cure in Fig. 28. Authors also suggested that chemical strains had completed before the degree of cure was fully developed and their contribution to residual stress was very little.

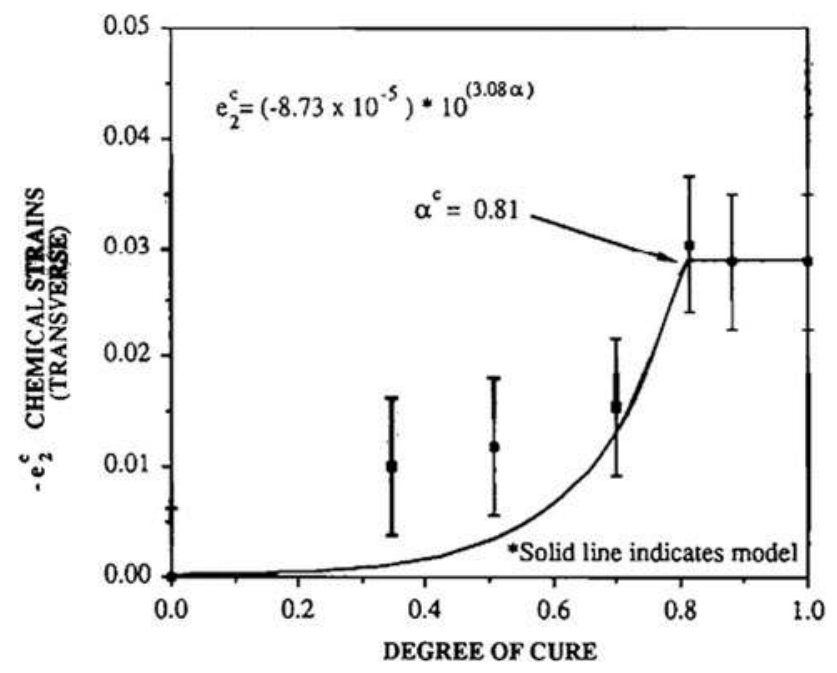

Fig. 28 Transverse chemical strain of a single ply of composite
Cooling of plies on removal from oven induces thermal strain, which is difficult to deduct from total strain. Shrinkage determined in this study is the apparent shrinkage. As described earlier, apparent Sh may be much lower than the actual Sh. Manual measurement, curing under atmospheric pressure and experiments on only unidirectional composites are the limitation of this method.

\section{Warpage}

Daniel et al. [87] which followed the warpage of 16 plies unidirectional glass/epoxy laminated plate. These uncured 16 plies were stacked over a fully cured 16 ply plate having same stacking sequence. During the curing, uncured portion shrank chemically, whereas no such phenomenon occurred in cured portion. Due to this mismatch, warpage occurred in the sample, which was recorded using shadow moiré method. Curing temperature as a function of time, and a line diagram of measurement setup are shown in Fig. 29a, b. A pressure of $2.3 \mathrm{MPa}$ was maintained during the curing.

It was assumed that both uncured and cured portion undergo the same T.E. Therefore, warpage was assumed zero during heating or cooling in the absence of Sh. From the warpage of this 32 ply sample, curing strain of 16 ply uncured prepreg was calculated. The Sh strain was found equal to $e_{x}=1.540 \times 10^{-4}$ and $e_{y}=2.779 \times 10^{-4}$.

Similar method is used by Hu et al. [88], Zhu et al. [89] and Ken and Masumi [90] for the characterization of Sh in a specific direction.

This method is presents a good way to observe the effect of Sh in the composite. But it did not provide quantitative values of Sh. Results obtained are the values of chemical strains, which may be only due to a part of total Sh occurred in the resin.

A significant advantage of this method is its ability to provide measurement throughout the curing. Here, this method was used for a composite having all the plies at $0^{\circ}$
Fig. 29 a Temperature cycle for curing the composite b experimental setup for measuring out-of-plane deflection [87]
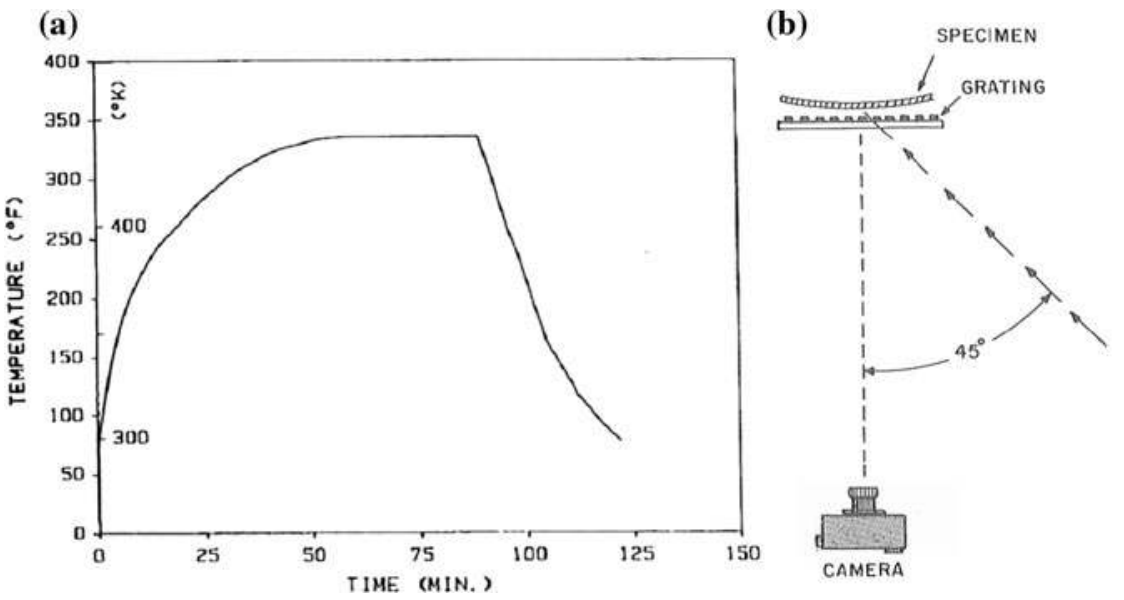

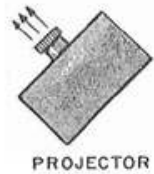


and a curvature along $z$-axis was observed, but for the composites with complex stacking sequences, it is very difficult to deconvolute the strains along $x, y$ and $z$-axis. Moreover, use of adhesive between uncured and cured portion, flow of resin during curing may also affect the quality of results.

\section{Strain gauge method}

Crasto et al. [91] studied 16-ply unidirectional (AS4/35016) graphite/epoxy composites from Hexcel. The build-up of residual strains during composite cure was measured with WK-00-250BG-350 strain gauges from Micro Measurements, Inc. Size of a sample was equal to $15.2 \times 15.2 \mathrm{~cm}$. The strain gauges were bonded to the surface plies and/or embedded at the mid-plane at a location at least $1.3 \mathrm{~cm}$ from a free edge.

Curing was done in an autoclave, while plies were vacuum bagged. The sketch of setup is shown in Fig. 30 . Using a gauge from the same production lot, bonded to an ultra-low CTE titanium silicate block, as part of the

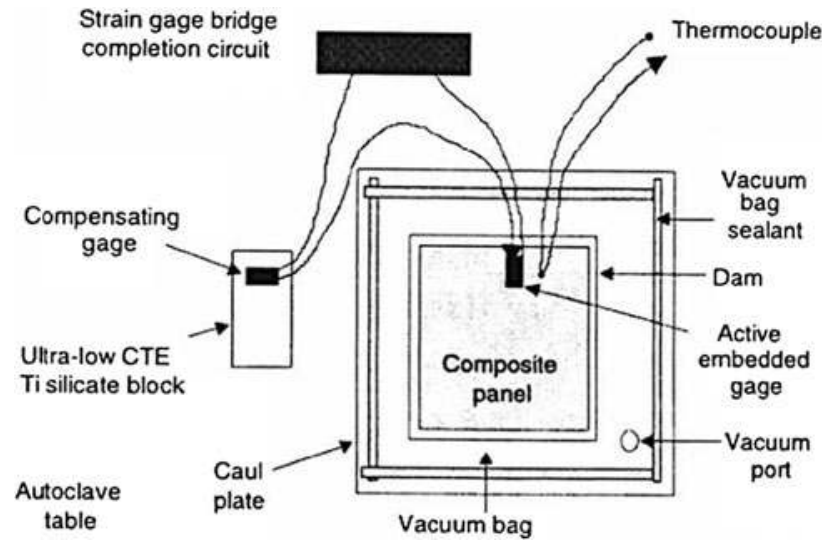

Fig. 30 Sketch of strain gauge measurement setup [91]

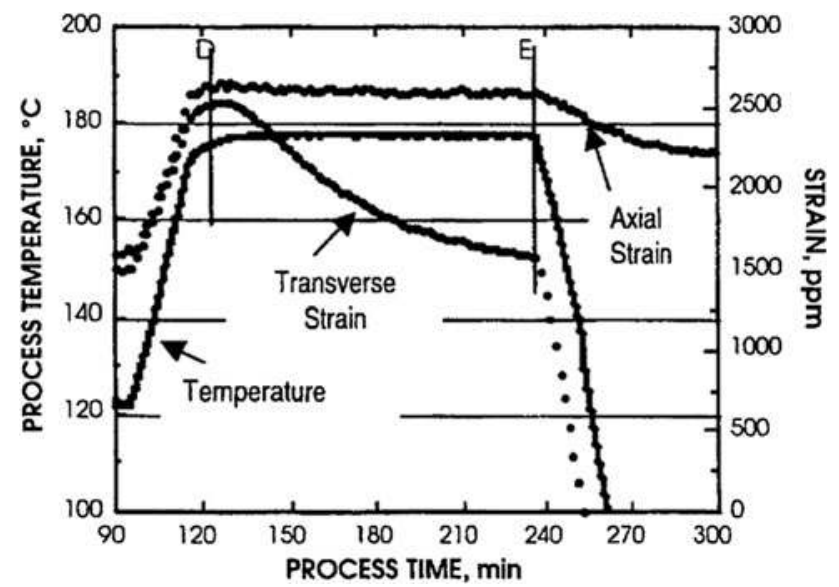

Fig. 31 Curing strains and temperature versus processing time
Wheatstone half-bridge, the output of the active gauge was compensated for temperature and pressure variations in the autoclave to yield the strain arising solely from composite cure.

An example of results is shown in Fig. 31, where temperature cycle and longitudinal and transversal strains are plotted versus processing time. Between points $\mathrm{D}$ and $\mathrm{E}$, when temperature was constant, a significant amount $(1500 \mathrm{ppm})$ of transverse strain was observed. This corresponds to Sh of composite. The strain along fibres (longitudinal strain) was negligible.

Sakaguchi et al. [92] used strain gauges to measure the Sh of dental composites. Kim [93] also used strain gauges to measure curing strains of carbon/epoxy composite during curing by resin transfer moulding (RTM) process.

This method provides simultaneously the strains in two directions. But the presence of gauges can change the local stiffness of composite and hence may affect the results.

This technique is able to detect the strain induced in the composite due to Sh. Such strain induces only when properties of matrix have developed significantly. It means the measured values of strains correspond to only a portion of total Sh. A relation between Sh and induced strain may help to find the amounts of Sh occurred actually.

\section{Fibre optic sensors}

Fibre optic sensors have been used by several authors [9497] for the measurement of cure strains and residual stresses of composites.

Testing principle of two such sensors: Extrinsic FabryPerot interferometer (EFPI) sensor, and FBG are given below with an example of results given by each sensor. The tests were conducted on Carbon Fibre Reinforced Plastic (CFRP) composite samples, made from 16 plies of Hexcel 920 prepreg with different stacking sequences. Thickness of each sample was about $2 \mathrm{~mm}$. Curing was done in a heating press. Several sensors were placed within the laminated plate at different positions.

Extrinsic Fabry-Perot interferometer (EFPI) sensor The basic principle of the EFPI sensor used by Leng and Asundi [98] was based on the multi-reflection Fabry-Perot interference between two reflecting mirrors. The schematic configuration of the EFPI sensor is shown in Fig. 32a. The EFPI sensor was made using a single-mode optical fibre and a multi-mode fibre as the two reflectors. Two fibres were inserted and fused into a quartz capillary tube with a larger diameter. An epoxy adhesive was used to reinforce the join points with the capillary. The cavity comprised two reflectors that were parallel to each other and perpendicular to the axis of the optical fibres. The cavity length between the two surfaces of the optical fibres changes due to the 
(a)

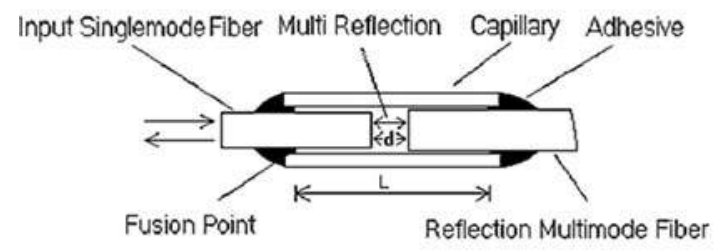

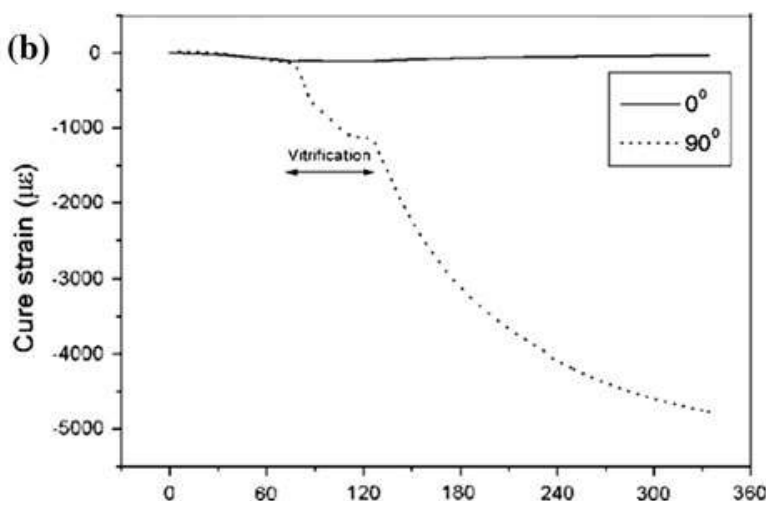

Fig. 32 a Schematic of EFPI sensor $\mathbf{b}$ curves of longitudinal and transverse cure strains of CFRP composite laminates $\left(0_{4} / 90_{4} / 90_{4} / 0_{4}\right)$ using the EFPI sensor

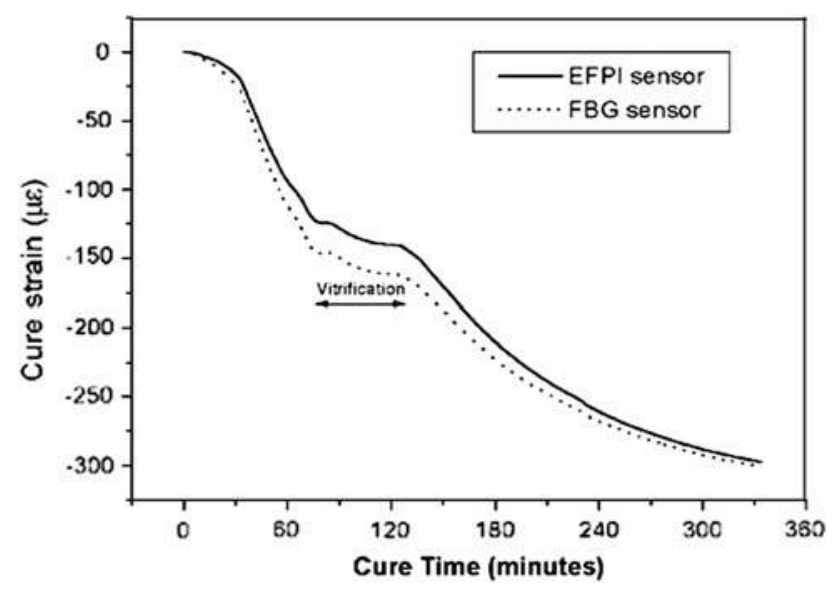

Fig. 33 Comparison curves of longitudinal cure strain of CFRP composite laminates $\left(0_{4} / 90_{4} / 90_{4} / 0_{4}\right)$ with damage using the EFPI and FBG sensors

application of mechanical load or thermal or chemical strain. This change was determined using a Fabry-Perot interferometer. The measured cured strain along fibre direction $\left(0^{\circ}\right)$ and perpendicular to the fibre direction is presented in Fig. 32b. As expected, the transversal cure strain is much higher than the longitudinal strain. Moreover, authors were able to observe the vitrification with this setup.

FBG sensor An example of cure strain measured by FBG sensor placed within 16 ply laminated composite is shown in the Fig. 33. Authors also made a comparison of these results with those obtained using EFPI sensor.

Similar to warpage and strain gauge method, this technique also provides the values of chemical strains occurred due to Sh. Actual value of Sh can be determined by finding its exact relation with these strains. The presence of an external object within composite certainly affects the results, which should be considered with this technique.

\section{Thermo-mechanical analyser}

Olivier [99] adapted TMA to determine the in-plane Sh and thermo-mechanical mechanical properties of laminated composite samples during curing.

Several $25 \times 2.5 \mathrm{~mm}$ unidirectional and cross-ply samples with various stacking sequences were prepared from a unidirectional prepreg tape. Sample was hold and connected to TMA through the steel clamping jaws as shown in Fig. 34. The pin joints allowed the free rotation of sample about $y$-axis. Any change in dimension along the sample axis was detected by LVDT sensor of TMA along with sample temperature.

An example of strain result for $[90]_{4}$ sample and temperature cycle are plotted versus time in Fig. 35. A clear evolution of strain with temperature cycle can be noted. The strain recorded during the isothermal portion of temperature cycle is related to Sh.

Partially cured sample are required for testing on this instrument. This setup provides good results for samples having only in-plane strain, but the presence of out-ofplane deflection such as in case of [0/90] can affect the quality of results. Moreover, the sample cannot be subjected to pressure and vacuum during the experiments. To relate the strain with degree of cure, another instrument such as DSC is required.

\section{Dynamic mechanical analyser}

Ersoy and Tugutlu [100] used DMA for through the thickness Sh strain measurement of cross-ply (XP) and unidirectional (UD) carbon/epoxy (AS4/8552 by Hexcel Composites) composite material. Each sample contained 26 plies, and was $5 \mathrm{~mm}$ thick.

TA Instruments Q800 Dynamic Mechanical Analyser was used in compression mode with the appropriate compression clamps to test $25 \times 25 \mathrm{~mm}^{2}$. The partially cured sample was placed on the flat surface of the fixed bottom 
Fig. 34 Perkin-Elmer TMA7 extension device for in-plane displacement measurement

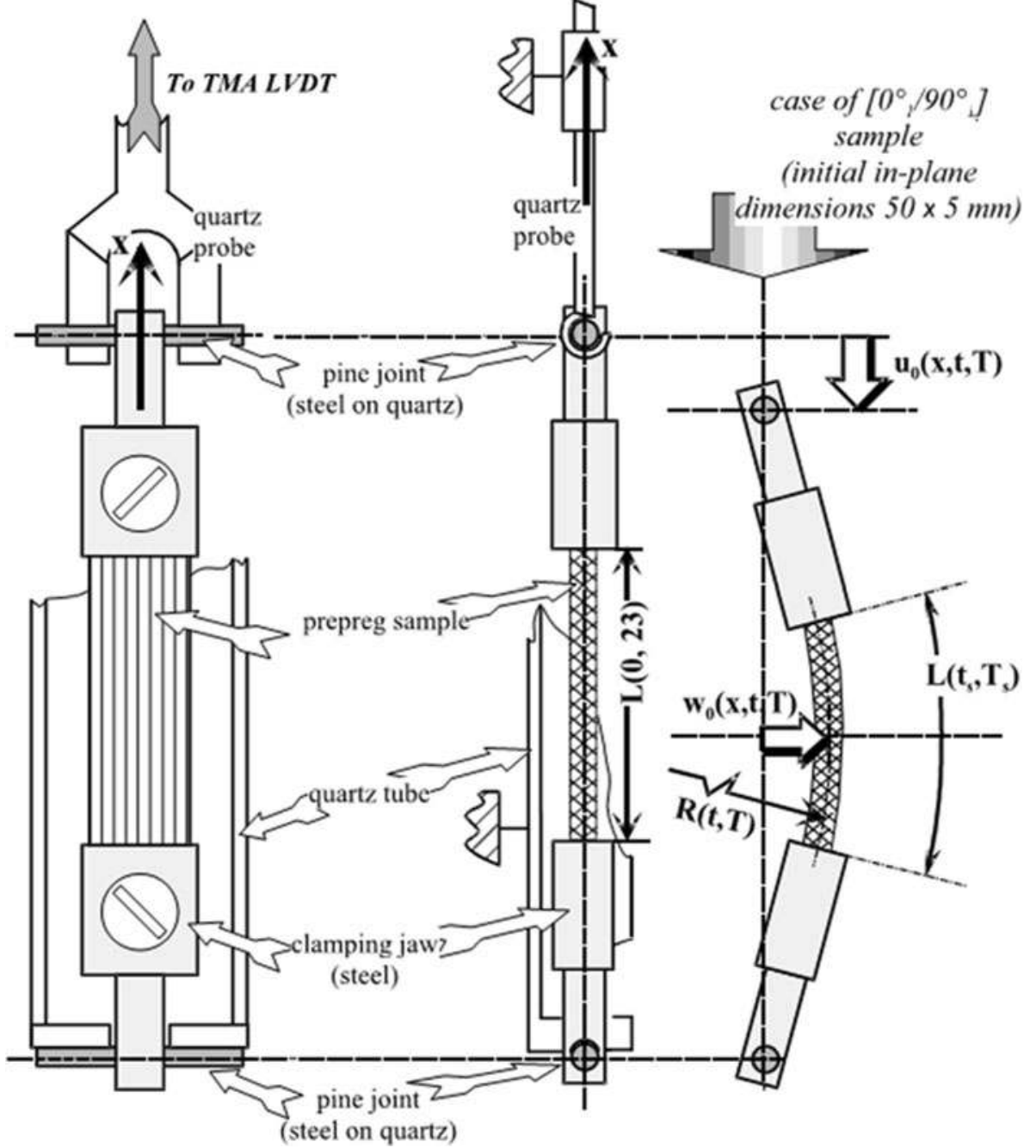

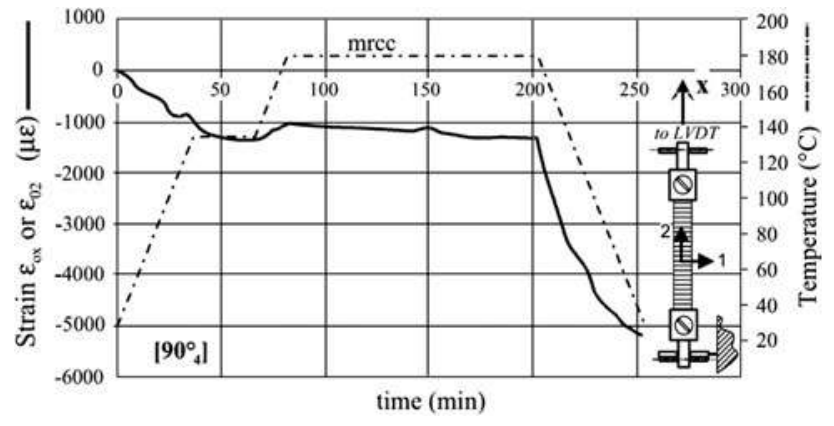

Fig. 35 Curing strain of $[90]_{4}$ composite versus time

clamp and the moving top clamp applied a very small force $(0.1 \mathrm{~N})$ on the sample to hold it. The displacement of this clamp during curing provided dimensional changes of the sample. DSC was used to determine the degree of cure.

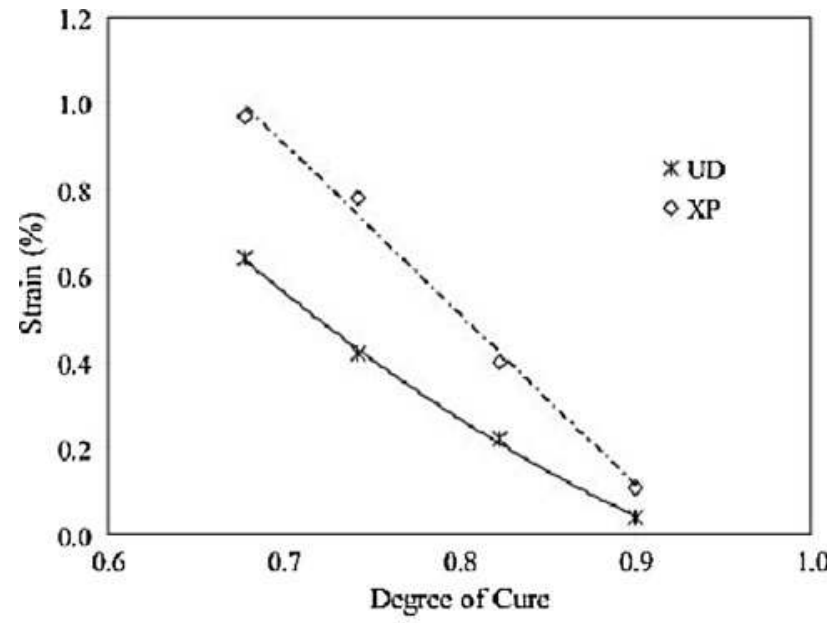

Fig. 36 Experimental setup for measuring out-of-plane shrinkage versus degree of cure 
Figure 36 shows the through the thickness Sh (strain \%) of cross-ply and unidirectional composite sample versus degree of cure. A significant difference of stacking sequence of Sh can be noted.

This is a simple method to determine Sh of composite in a specific direction. But for measurement on this setup, partially cured samples are required. This means that information on shrinkage is available only after a certain degree of cure, e.g. gel point. Moreover, another instrument such as DSC is required for degree of cure measurement. Though a little, mechanical consolidation may also affect the results.

\section{Using video camera}

Garstka et al. [101] used a non-contact video extensometer to measure through the thickness curing strain of UD and cross-ply carbon/epoxy (16 ply, about $4 \mathrm{~mm}$ thick) laminated composite (AS4/8552) plates. Sample was placed between two steel plates. Following the position of targets marked on the steel plates by a video extensometer (Fig. 37), thickness of composite was recorded at a frequency of $20 \mathrm{~Hz}$.

The average values of post gel shrinkage were found to be $0.48 \%$ for unidirectional and $0.98 \%$ for cross-ply laminates, respectively. Authors held lateral contraction, which was completely constrained, responsible for the almost double through the thickness Sh strain in cross-ply laminates. Effect of consolidation on thickness variation was also discussed in detail in this paper. Authors made a comparison of their measurements with the value of volume Sh of same resin, showing that they were able to measure almost whole through the shrinkage of resin after gel point.

Ifju et al. used a cure reference method [102, 103] for the measurement of curing strains of 16 ply AS4/3501-6 graphite/epoxy composite with different stacking sequences. The method involves the replication of diffraction

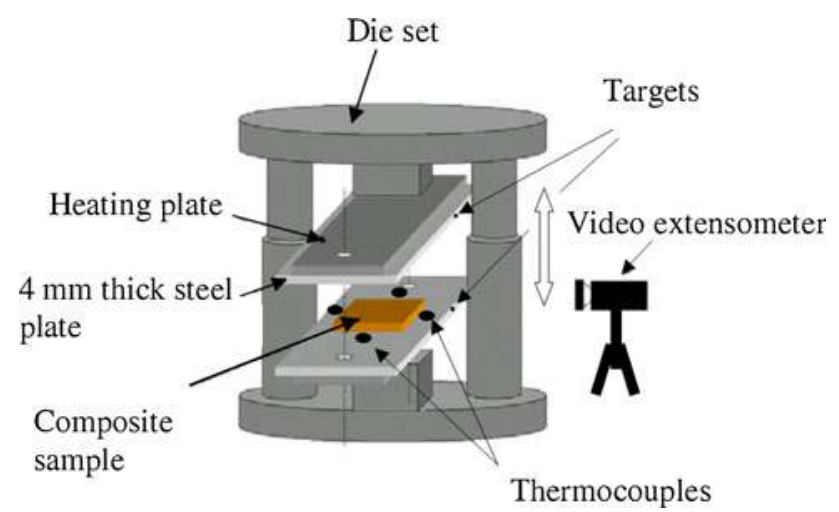

Fig. 37 Transverse chemical strain of a single ply of composite gratings onto the surface of composite specimens during the autoclave curing. Residual strains associated with the curing process were measured using moiré interferometry at room temperature after the specimens were taken out of the autoclave.

Removal of sample for strain recording may lead to the different results as compared to in situ measurement.

\section{Conclusion}

It can be concluded from the above literature survey that the most difficult step to determine the Sh is its decoupling from T.E. The choice of shrinkage measurement technique is dependent on many factors. For example, if an inexpensive and simple technique is required, a capillary-type dilatometer is the best choice. However, measurement can be taken under atmospheric pressure and at room temperature. Moreover, sticking of resin with walls, manual readings affect the quality of results. Gravimetric method is a good alternative of capillary-type dilatometers but they lack the measurement under pressure conditions. Plungertype dilatometers provide measurement under high temperature and pressure conditions along with measurement of degree of cure from the same experiment. But the contribution of pouch containing resin may affect the quality of results.

Techniques like Rheometer, DMA and TMA require partially cured samples for the measurements. Moreover, sample sizes are very small. Pycnometer gave good results at room temperature only if there is no exothermy of reaction or change of temperature during curing. Measurement using ultrasonic waves is also very sensitive to temperature change during curing. FBG is very good techniques for online monitoring of Sh and mechanical properties of resin during curing. However, care should be taken to deduct the effect of presence of thermocouples and sensors within the resin sample, which might affect the results by changing the local mechanical properties of matrix.

Most of the authors neglected the thermal gradients while calculating the Sh of resin, and with some exceptions, in majority of studies it was found that Sh has a linear relationship with degree of cure.

In most of the techniques, two different instruments were used for $\mathrm{Sh}$ and degree of cure measurement. If amount of resin tested on both instruments is different, higher exothermy in larger amount sample will change its rate of reaction and will affect the results. Therefore, care should be taken while selecting the amount of resin in such cases.

Despite several reported techniques in the literature, the studies on Sh of composite are not so often. In general, it is 
believed that volume Sh of composite is equal to Sh of resin volume present in that composite. However, in most of the studies reported in the literature, this was found not true. It has been observed that the Sh varies with fibre volume fraction and orientation of plies. The mostly used technique for determining volume $\mathrm{Sh}$ is a plunger-type dilatometer. Sh determined by this technique was linear as a function of degree of cure.

Using the optical sensors or strain gauges is a good for the simultaneous measurement of in-plane Sh along both axes. Pressure on strain gauge can affect the results. Moreover, the presence of these sensors may change the local mechanical properties. Therefore, care should be taken in this regard.

TMA gave repeatable results on shrinkage measurements, but pressure cannot be applied during the curing on the composite samples. Information on shrinkage before the gel point is not available on DMA and TMA as partially cured samples are required for the testing.

\section{References}

1. Abou Msallem Y, Jacquemin F, Boyard N, Poitou A, Delaunay D, Chatel S (2010) Compos Part A 41(1):108. doi:10.1016/ j.compositesa.2009.09.025

2. Shimbo M, Yamabe M, Miyano Y (1998) Viscoelastic analysis of residual stress in thermosetting resins introduced during curing process. In: Allison IM (ed) 11th International conference on experimental mechanics, Oxford, p 1325

3. Hodges J, Yates B, Darby MI, Wostenholm GH, Clemmet JF, Keates TF (1989) J Mater Sci 24(6):1984. doi:10.1007/ bf02385410

4. Lingois P, Berglund L, Greco A, Maffezoli A (2003) J Mater Sci 38(6):1321. doi:10.1023/a:1022811315807

5. Bogetti TA, Gillespie JW (1992) J Compos Mater 26(5):626. doi: $10.1177 / 002199839202600502$

6. Harris B (1978) J Mater Sci 13(1):173. doi:10.1007/bf00739288

7. Kim KS, Hahn HT (1989) Compos Sci Technol 36(2):121. doi: 10.1016/0266-3538(89)90083-3

8. White SR, Kim YK (1998) Mech Compos Mater Struct 5(2): 153. doi:10.1080/10759419808945897

9. Hahn HT, Pagano NJ (1975) J Compos Mater 9(1):91. doi: $10.1177 / 002199837500900110$

10. Lee S, Schile R (1982) J Mater Sci 17(7):2095. doi:10.1007/ bf00540428

11. Wisnom MR, Gigliotti M, Ersoy N, Campbell M, Potter KD (2006) Compos Part A 37(4):522

12. Yoon KJ, Kim J-S (2001) J Compos Mater 35(3):253. doi: $10.1177 / 002199801772662244$

13. Dano M-L, Hyer MW (1998) Int J Solids Struct 35(17):2101. doi:10.1016/s0020-7683(97)00167-4

14. Nawab Y, Jaquemin F, Casari P, Boyard N, Sobotka V (2013) J Compos Mater 47(3):327. doi:10.1177/0021998312440130

15. Chekanov YA, Korotkov VN, Rozenberg BA, Dhzavadyan EA, Bogdanova LM (1995) Polymer 36(10):2013. doi:10.1016/ 0032-3861(95)91446-E

16. Eom Y, Boogh L, Michaud V, Sunderland P, Månson JA (2004) Polym Eng Sci 41(3):492
17. ASTM (2012) Standard test method for linear shrinkage of cured thermosettings casting resins during cure. ASTM D2566-79

18. Starkweather HW, Taylor GB (1930) J Am Chem Soc 52(12): 4708. doi:10.1021/ja01375a011

19. Li C, Potter K, Wisnom MR, Stringer G (2004) Compos Sci Technol 64(1):55

20. Zhang J, Xu YC, Huang P (2009) Express Polym Lett 3(9):534

21. Madhukar MS, Genidy MS, Russell JD (2000) J Compos Mater 34(22):1882. doi:10.1106/hucy-dy2b-2n42-ujbx

22. Boyard N, Millischer A, Sobotka V, Bailleul JL, Delaunay D (2007) Compos Sci Technol 67(6):943. doi:10.1016/j.compscitech. 2006.07.004

23. Li W, Lee LJ (1998) Polymer 39(23):5677. doi:10.1016/S00323861(98)00074-3

24. Nawab Y, Tardif X, Boyard N, Sobotka V, Casari P, Jacquemin F (2012) Compos Sci Technol 73:81. doi:10.1016/j.compscitech. 2012.09.018

25. Pingsheng H, Zhiqiang Z, Caiyuan P, Renjie W (1989) J Mater Sci 24(5): 1528. doi:10.1007/BF01105666

26. Yates B, McCalla BA (1979) J Mater Sci 14:1207. doi: 10.1007/BF00561306

27. Snow AW, Armistead JP (1991) Dilatometry on thermoset resins. Naval Research Laboratory, Washington, DC

28. Huang Y-J, Liang C-M (1996) Polymer 37(3):401. doi: 10.1016/0032-3861(96)82909-0

29. Parlevliet PP, Bersee HEN, Beukers A (2010) Polym Test 29(4):433

30. Khoun L, Hubert P (2010) Polym Compos 31(9):1603. doi: $10.1002 / \mathrm{pc} .20949$

31. Russell JD, Madhukar MS, Genidy MS, Lee AY (2000) J Compos Mater 34(22):1926. doi:10.1106/uy9u-f2qw-2fkk-91kg

32. Zoller P, Bolli P, Pahud V, Ackermann H (1976) RevSciInstrum 47(8):948

33. Li W, Lee LJ (2000) Polymer 41(2):685

34. Ramos JA, Pagani N, Riccardi CC, Borrajo J, Goyanes SN, Mondragon I (2005) Polymer 46(10):3323

35. Kinkelaar M, Muzumdar S, Lee LJ (1995) Polym Eng Sci 35(10):823

36. Hwang SJ, Chang YS (2005) J Polym Sci Part B 43(17):2392. doi: $10.1002 /$ polb. 20540

37. Kinkelaar M, Lee LJ (1992) J Appl Polym Sci 45(1):37

38. Kinkelaar M, Wang B, Lee LJ (1994) Polymer 35(14):3011

39. Saraswat MK, Jansen KMB, Ernst LJ (2006) CORD Conf Proc 2:782. doi:10.1109/estc.2006.280100

40. Nawab Y, Boyard N, Sobotka V, Casari P, Jacquemin F (2011) Adv Mater Res 326:19

41. Millischer A (2000) Transferts thermiques dans le procede d'injection BMC (Bulk Molding Compound). Université de Nantes, Nantes

42. Boyard N, Vayer M, Sinturel C, Erre R, Delaunay D (2004) J Appl Polym Sci 92(5):2976. doi:10.1002/app.20312

43. Massé H, Arquis É, Delaunay D, Quilliet S, Le Bot PH (2004) Int J Heat Mass Transf 47(8-9):2015

44. Nawab Y, Casari P, Boyard N, Jacquemin F (2013) J Mater Sci 48(6):2394. doi:10.1007/s10853-012-7026-6

45. Aduriz X, Lupi C, Boyard N, Bailleul JL, Leduc D, Sobotka V, Lefèvre N, Chapeleau X, Boisrobert C, Delaunay D (2007) Compos Sci Technol 67(15):3196

46. Bucknall CB, Partridge IK, Phillips MJ (1991) Polymer 32(4):636. doi:10.1016/0032-3861(91)90475-X

47. Ochi M, Yamashita K, Shimbo M (1991) J Appl Polym Sci 43(11):2013. doi:10.1002/app.1991.070431108

48. Magniez K, Vijayan A, Finn N (2012) Polym Eng Sci 52(2):346. doi:10.1002/pen.22088

49. Stone MA, Fink BK, Bogetti TA, Gillespie JW (2000) Polym Eng Sci 40(12):2489 
50. Flores F, Gillespie JW, Bogetti TA (2002) Polym Eng Sci 42(3):582

51. Lange J, Toll S, Månson J-AE, Hult A (1995) Polymer 36(16):3135

52. Schoch KF, Panackal PA, Frank PP (2004) Thermochim Acta 417(1):115

53. Ruiz E, Trochu F (2005) J Compos Mater 39(10):881

54. Tai HJ, Chou HL (2000) Eur Polym J 36:2213

55. Brauner C, Block TB, Purol H, Herrmann AS (2012) J Compos Mater 46(17):2123

56. Hong Y, Subodh GM, Ee Hua W (2005) Macromol Rapid Commun 26(18):1483

57. Zarrelli M, Partridge IK, D'Amore A (2006) Compos Part A 37(4):565

58. Zarrelli M, Skordos AA, Partridge IK (2002) Plast Rubber Compos 31:377

59. Yu H, Mhaisalkar SG, Wong EH (2005) J Electron Mater 34(8):1177. doi:10.1007/s11664-005-0248-5

60. Haider M, Hubert P, Lessard L (2007) Compos Part A 38(3):994

61. Shah DU, Schubel PJ (2010) Polym Test 29(6):629

62. Khoun L, Centea T, Hubert P (2010) J Compos Mater 44(11): 1397. doi: $10.1177 / 0021998309353960$

63. Cook WD, Forrest M, Goodwin AA (1999) Dent Mater 15(6): 447

64. Shimbo M, Ochi M, Shigeta Y (1981) J Appl Polym Sci 26(7):2265. doi:10.1002/app.1981.070260714

65. Hoa SV, Ouellette P, Ngo TD (2009) J Compos Mater 43(7):783. doi:10.1177/0021998308102035

66. Parlevliet PP, Bersee HEN, Beukers A (2010) Polym Test 29(3):291

67. Antonucci V, Giordano M, Cusano A, Nasser J, Nicolais L (2006) Compos Sci Technol 66(16):3273. doi:10.1016/j.compscitech. 2005.07.009

68. Karalekas D, Cugnoni J, Botsis J (2008) Compos Part A 39(7):1118. doi:10.1016/j.compositesa.2008.04.010

69. Giordano M, Laudati A, Nasser J, Nicolais L, Cusano A, Cutolo A (2004) Sens Actuators A 113(2):166. doi:10.1016/j.sna. 2004.02.033

70. Vacher S, Molimard J, Gagnaire H, Vautrin A (2003) Polym Polym Compos 12(4):269

71. Wang Y, Han B, Kim DW, Bar Cohen A, Joseph P (2008) Exp Mech 48(1):107. doi:10.1007/s11340-007-9067-3

72. Harsch M, Karger-Kocsis J, Herzog F (2007) Polym Lett 1(4):226

73. Wang Y, Woodworth L, Han B (2011) Exp Mech 51(7):1155. doi:10.1007/s11340-010-9410-y

74. Othonos A, Kalli K (1999) Fiber Bragg gratings: fundamentals and applications in telecommunications and sensing. Artech House, Norwood
75. Thomas CL, Bur AJ (1999) Polym Eng Sci 39(9):1619

76. Fano V, Ortalli I, Pizzi S, Bonanini M (1997) Biomaterials 18(6):467

77. Ochi M, Yamashita K, Shimbo M (2003) J Appl Polym Sci 43(11):2013

78. Plepys A, Farris R (1990) Polymer 31(10):1932

79. Sun J, Eidelman N, Lin-Gibson S (2009) Dent Mater 25(3):314

80. Sharp LJ, Choi IB, Lee TE, Sy A, Suh BI (2003) J Dent 31(2):97

81. Russell J (1993) SAMPE Q 24(2):28

82. Sadeghinia M, Jansen KMB, Ernst LJ (2012) Int J Adhesion Adhesives 32:82. doi:10.1016/j.ijadhadh.2011.10.007

83. Millischer A, Delaunay D (2001) J Reinf Plast Compos 20(6):495

84. Prasatya P, McKenna GB, Simon SL (2001) J Compos Mater 35(10):826. doi:10.1177/002199801772662424

85. Holst M, Schänzlin K, Wenzel M, Xu J, Lellinger D, Alig I (2005) J Polym Sci Part B 43(17):2314

86. White S, Hahn H (1992) J Compos Mater 26(16):2423

87. Daniel IM, Wang T-M, Karalekas D, Gotro JT (1990) J Compos Technol Res 12(3):172

88. Hu G, Luan J-E, Chew S (2009) J Electron Packag 131(1):14466

89. Zhu WH, Guang L, Wei S, Che FX, Sun A, Wang CK, Tan HB, Zhao BZ, Chin NH (2007) Thermal, mechanical and multiphysics simulation experiments in microelectronics and microsystems, 2007. EuroSime 2007. International Conference on, 16-18 April 2007, p 1

90. Ken O, Masumi S (2001) Polym Eng Sci 41(8):1373

91. Crasto AS, Kim RY, Russell JD (2002) Polym Compos 23(3):454

92. Sakaguchi RL, Versluis A, Douglas WH (1997) Dent Mater 13(4):233. doi:10.1016/s0109-5641(97)80034-6

93. Kim YK (2004) J Compos Mater 38(11):959

94. Murukeshan V, Chan P, Ong L, Seah L (2000) Sens Actuators A 79(2): 153

95. Kalamkarov A, Fitzgerald S, MacDonald D (1999) Compos B Eng 30(2): 167

96. Lawrence CM, Nelson DV, Bennett TE, Spingarn JR (1997) SPIE, $p 154$

97. Mulle M, Collombet F, Olivier P, Zitoune R, Huchette C, Laurin F, Grunevald YH (2009) Compos Part A 40(10):1534

98. Leng JS, Asundi A (2002) Smart Mater Struct 11:249

99. Olivier PA (2006) Compos Part A 37(4):602

100. Ersoy N, Tugutlu M (2009) Polym Eng Sci 50(1):84

101. Garstka T, Ersoy N, Potter K, Wisnom M (2007) Compos Part A 38(12):2517

102. Ifju PG, Kilday BC, Niu X, Liu S-C (1999) J Compos Mater 33(16): 1511. doi:10.1177/002199839903301603

103. Ifju P, Niu X, Kilday B, Liu S, Ettinger S (2000) Exp Mech 40(1):22 